
\title{
28 Resarch Square \\ Combined Lubrication of Surface Texturing and Copper Covering for Broaching Tool
}

\author{
NI Jing \\ Hangzhou Dianzi University \\ Kai Feng \\ Hangzhou Dianzi University \\ Zhuang Kai \\ Hangzhou Dianzi University \\ Sang Zhiqian \\ Hangzhou Dianzi University \\ Meng Zhen \\ Hangzhou Dianzi University \\ Md Mizanur Rahman ( $\nabla$ mizanur_rahman@hdu.edu.cn ) \\ Hangzhou Dianzi University https://orcid.org/0000-0002-2654-7667
}

\section{Research Article}

Keywords: Textured tool, copper covering, Chip thickness, Curling radius, Broaching

Posted Date: June 22nd, 2021

DOl: https://doi.org/10.21203/rs.3.rs-632101/v1

License: (c) (1) This work is licensed under a Creative Commons Attribution 4.0 International License.

Read Full License 


\title{
Combined Lubrication of Surface Texturing and Copper Covering for Broaching Tool
}

\author{
Jing Ni, Kai Feng, Kai Zhuang, Zhiqian Sang, Zhen Meng, Md Mizanur Rahman* \\ School of Mechanical Engineering, Hangzhou Dianzi University, Hangzhou 310005, PR China \\ Corresponding author: mizanur_rahman@hdu.edu.cn (M. M. Rahman)
}

\begin{abstract}
The broaching tool is an efficient and precisely heavy-loaded metal-cutting tool, widely used in the mass production of key components related to the aerospace and automobile industries. However, the heavy load, intense squeezing, and friction in the tool-chip contact area prevent the cutting fluid from entering the desired location. Consequently, insufficient lubrication gives rise to a hightemperature built-up edge, thereby lowering machining accuracy and efficiency. To reduce frictional force, three textures (i.e., micro-pit, stripe, mesh) are prepared on the rake face of broaching tool with laser processing technique. Afterward, textured grooves are covered with copper using the reciprocating rotational friction; this artifact enhances the system's wettability and heat dissipation ability. Experiments approve that compared to the non-textured cutting teeth, the cutting force with the stripe-textured teeth is reduced by $7.6 \%$. Nevertheless, the cutting force is decreased by $14.6 \%$ after covering the tool surface with copper. Obtained results indicate that the wettability of cutting fluid on the surface is improved. In addition, convex peaks on the tool surface are passivated during the reciprocating rotation of the copper bar.
\end{abstract}

Keywords: Textured tool; copper covering; Chip thickness; Curling radius; Broaching

\section{Introduction}

Arrazola et al. (2020) have reported that broaching tool has multiple rows of teeth for roughing, semi-finishing, and finishing, respectively, and is frequently used in mass production due to its high efficiency. However, Zhang et al. (2011) have proved that because of the heavy load, strong friction and extrusion occur between the tool and the workpiece during the cutting process, reducing the tool's service life, surface quality and machining accuracy of the workpiece. Kümmel et al. (2015) and Rao et al. (2018) have pointed out that the introduction of cutting fluid and surface texture technology modifies the friction state on the tool-chip interface to augment cutting performance. Furthermore, broaching is a closely teethed cutting process. The cutting fluid cannot be sprayed directly onto the surface of the contact area between the tool and the workpiece, resulting in insufficient lubrication at the defined area. Therefore, texture has received much attention due to its ability to reduce contact area and store cutting fluid.

In recent years, research has been carried out to fabricate different textures on diverse tool surfaces using various processing technologies. Koshy and Tovey (2011) used electrical discharge machining (EDM) to generate anisotropic texture on the rake face of the turning tool, intending to improve lubricant penetration and retention. Results showed that the existence of surfaces improved the friction state of the tool-chip interface. Niketh and Samuel (2017) created dimpled textures on the flute and margin side of the drill tool using the laser micromachining technique. Experimental results proved that surfaces of the drill tool were able to reduce frictional force in the cutting area for Ti-6Al-4V machining. Zhou et al. (2019) used a laser to prepare a micro-groove texture on the 
rake face of the milling tool and conducted experiments under two different coolant conditions. The surface enhanced the physical lubrication film formed on the tool-chip interface and improved the lubrication effect. Ahmed et al. (2020) fabricated different textures on the rake face of the cutting tool by femtosecond laser, afterward performed comparison tests for turning to the machine of AISI 304. Results revealed that maximum reductions in cutting force, feed force, and coefficient of friction were $58 \%, 100 \%$, and $24 \%$, respectively, for the square textured tool. Ge et al. (2019) fabricated textures in different groove widths on the rake face of the turning tool by femtosecond laser. They revealed that textures enhanced the penetration of cutting fluid, improved the lubrication of the tool-chip interface, and significantly reduced the cutting force compared to non-textured tools.

Moreover, Feng et al. (2019) used in-situ hot-press sintering technology to prepare ceramic tools with different morphological parameters to explore the best size and cutting parameters of microstructure morphology. Mashinini et al. (2020) applied the wire spark erosion machining technology to fabricate textures on the rake face of the turning tool. Both results showed that the textured tool effectively reduces the cutting force, temperature, and wear.

In summary, proper surface texture can reduce the friction of the tool-chip interface. The cutting fluid is stored to form micro-pool lubrication, which leads to a reduction in cutting force and temperature. The processing methods mentioned above have their benefits and drawbacks in flexibility, accuracy, and processing speed. In particular, laser processing technology is frequently used because of its wide acceptability and high efficiency.

Although textured tools perform well in reducing cutting force and temperature, the wearing between the tool and the material still affects tool life. Hence, Zhang et al. (2018) stated that surface coating and solid lubrication are usually introduced with textured tools. Textures enhance the bonding strength between coatings and textured surfaces; textures in different scales significantly affect the substrate's specific surface area and wettability. Obikawa et al. (2011) fabricated four types of micro-surface textures at the rake face of the cemented carbide turning tool by photolithography and covered surfaces of textured tools with diamond-like carbon (DLC). Results indicated that textured tool with coating effectively improved the lubrication conditions for machining aluminum alloy A6061-T6. Enomoto and Sugihara (2010) proposed a new type of micro/nano-combined micro-groove tool, on which DLC was deposited by arc ion plating. Subsequently, Enomoto and Sugihara (2011) found that the DLC coating significantly improved the anti-adhesion and lubrication properties of the textured surface in aluminum alloy milling experiments. Meng et al. (2021) reported a plasma-assisted laser machining approach to produce texture, and TiAIN was deposited on the textured tool by cathode arc evaporation technique. Results exhibited a pronounced reduction in cutting force compared to conventional covered tools in dry cutting of stainless steel. To improve the tribological property, the texture filled with solid lubrication has also been demonstrated by Moshkovith et al. (2007). Deng et al. (2013) used a femtosecond laser to prepare a nano-scale surface on the rake face close to the leading cutting edge of the $\mathrm{WC} / \mathrm{TiC} / \mathrm{Co}$ carbide tools; textured tools were then deposited with $\mathrm{WS}_{2}$ solid lubricant coatings. The deposition of a lubricating film on the textured surface was shown to be effective in

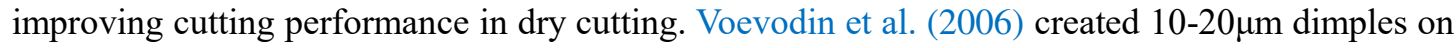
the surface of TiCN coatings by the laser texturing technique; then, the $\mathrm{MoS}_{2}$ was filled in the dimples. The performance of the textured film in terms of wear and friction exceeded that of monolithic TiCN films. Deng et al. (2012) processed three different types of textures on the rake face of $\mathrm{WC} / \mathrm{Co}$ cemented carbide tools, and the groove was filled with $\mathrm{MoS}_{2}$ solid lubricants. They 
reported that the elliptical textured tools with $\mathrm{MoS}_{2}$ have outstanding self-lubricating properties through the dry cutting test of carbon steel.

In the above literature, the coatings on textured tools are made by expensive materials, such as DLC, TiAlN, $\mathrm{WS}_{2}$, and $\mathrm{MoS}_{2}$, and their preparations are also complex. This hinders the broad applications of textured tools with coating on the multi-tooth surface of the broaching tool. In this paper, laser processing technology is used to prepare three types of textures on broaching tools. Copper with low hardness and excellent thermal conductivity is chosen as the covering material for textured grooves. The copper covering is made by a reciprocating rotational movement between the broaching tool and a copper bar, which has a reasonable cost. Comparative experiments are carried out on a horizontal internal broaching machine under MQL conditions. The performance of the textured broaching tool with the copper coating is evaluated based on the cutting force, chip thickness, and curling radius of the chip. The cutting mechanism using various textures broaching tools with copper coating for cutting steel 1045 is also investigated.

\section{Experimental details}

\subsection{Broaching tests}

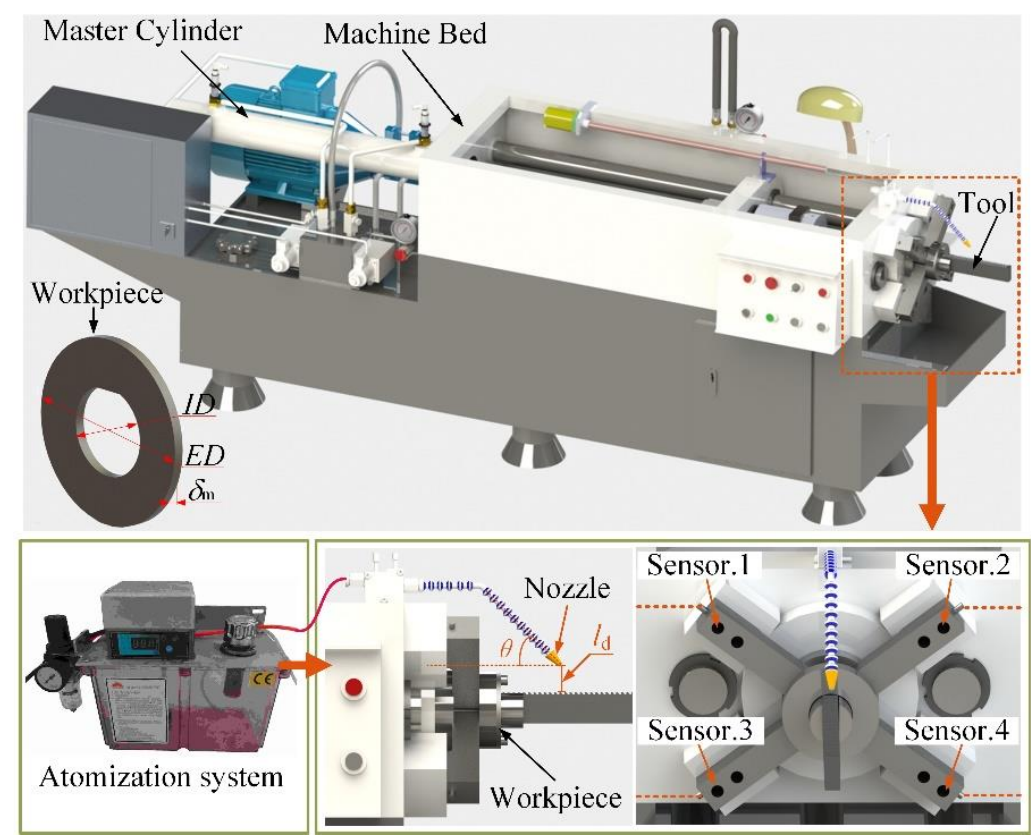

Fig. 1. Broaching experimental system.

As shown in Fig. 1, the experimental workpiece is made of steel 1045(AISI). The size of the workpiece is $90 \mathrm{~mm}$ in outer diameter $(O D), 41 \mathrm{~mm}$ in inner diameter $(I D)$, and $5 \mathrm{~mm}$ in thickness $\left(\delta_{\mathrm{m}}\right)$. The experiment system consists of broaching machine, force transducer, data acquisition instrument, and atomization system. A horizontal internal broaching machine (Changer LG612Ya800 ) is used in this experiment; parameters are given in Table 1. 
Table 1 Broaching machine and machining parameters

\begin{tabular}{ll}
\hline Parameter & Value \\
\hline Rated broaching force & $20 \mathrm{KN}$ \\
Maximum broaching stroke & $800 \mathrm{~mm}$ \\
Broaching speed & $80 \mathrm{~mm} / \mathrm{s}$ \\
Diameter of the master cylinder & $\varnothing 80 \mathrm{~mm} \times 45 \mathrm{~mm}$ \\
Oil pressure & $6 \mathrm{MPa}$ \\
\hline
\end{tabular}

The force transducer is for acquiring broaching force and is composed of four pressure sensors (CTY-204) and one amplifier with a maximum output voltage of $10 \mathrm{~V}$, a maximum load of $2 \mathrm{t}$, and a frequency response $50 \mathrm{~Hz}$. Data acquisition instrument (INV3018CT) with sample software (CIONV DASP V10) is applied to make sampling of data with a sampling frequency of $1 \mathrm{kHz}$. Based on the investigation of $\mathrm{Ni}$ et al. (2020), the cutting fluid with $10 \mathrm{wt} . \%$ castor oil and $1.5 \mathrm{wt} . \%$ surfactants, when added with linear alkylbenzene sulfonate, obtains the lowest broaching force and is selected as a cutting fluid for the experiment. An atomization nozzle with a working gas pressure of $7 \mathrm{bar}$ is applied to deliver cutting fluids into the cutting tool. A ramp angle $\theta=15^{\circ}$ with distance $l_{\mathrm{d}}=50 \mathrm{~mm}$ is used for the atomization nozzle to achieve the best lubrication and cooling.

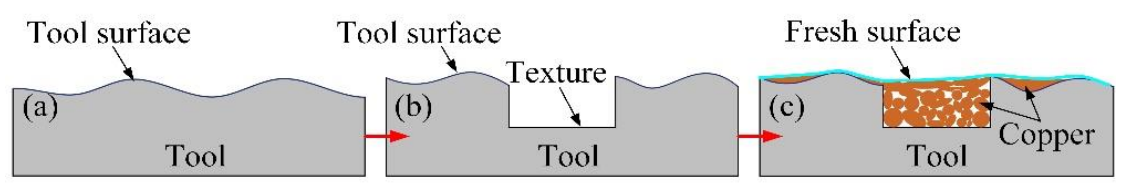

Fig. 2. The preparation process of tool surface: (a) initial surface and (b) textured surface, and (c) textured surface with copper.

Broaching tools under three working conditions are tested. Figure 2 depicts the preparation process of the tool surface in this test. For the first test, the tool's surface is not processed, and its surface is uneven on the microscopic scale, as exhibited in Fig. 2(a). The tool with fabricated texture on the surface, shown in Fig. 2(b), is used for the second test. For the last test, the surface of the textured tool is covered with copper, and a new flat surface is formed, as illustrated in Fig. 2(c).

\subsection{Preparation of textured tools}

The broaching tool is made from steel HSS-6542, with a length of $600 \mathrm{~mm}$, a width of $16 \mathrm{~mm}$, a front height of $35.1 \mathrm{~mm}$, and a gear height of $36.75 \mathrm{~mm}$, as illustrated in Fig. 3(a). The broaching tool has fifty cutting teeth in total divided into six parts, as demonstrated in Fig. 3(b). The first four parts (I-IV) are for roughing with the same feed per tooth of $0.04 \mu \mathrm{m}$, the fifth part is for semifinishing with the feed per tooth of $0.01 \mu \mathrm{m}$, and the sixth part is for finishing without the feed per tooth. Each tooth is with a rake angle of $12^{\circ}$, a clearance angle of $6^{\circ}$, and a pitch of $6 \mathrm{~mm}$. The rake faces of every ten teeth have the same texture prepared by a laser-marking machine (Han' s Laser H20); parameters are listed in Table 2. As shown in Fig. 3(c), the first ten teeth in Part I of broaching tool have no texture (denoted as NT). The micro-pitted surfaces are prepared on the cutting teeth in Part II (characterized as PT); the cutting teeth in Part III are striped textures (characterized as ST), and meshed surfaces are fabricated on Part IV teeth (denoted as MT). The depth-of-field photomicrographs of three-dimensional topography taken on the rake face of a textured tool are shown in Fig. 3(d). 
Table 2 Parameters of the laser processing system

\begin{tabular}{ll}
\hline Parameter & Value \\
\hline Power & $12 \mathrm{~W}$ \\
Spot diameter & $50 \mu \mathrm{m}$ \\
Frequency & $60 \mathrm{kHz}$ \\
Processing times & 10 \\
Repeat accuracy & $\pm 0.003 \mathrm{~mm}$ \\
\hline
\end{tabular}

Based on the actual condition of this experiment and the research by Obikawa et al. (2011), the dimension of textures is designed as follows, the size $a$ of the surface is $0.1 \mathrm{~mm}$, and the spacing of the texture $(b)$ is $0.25 \mathrm{~mm}$. The depth of texture is $0.06 \mathrm{~mm}$ under a consistent processing parameter. Significantly, the surface was treated with 2000-mesh sandpaper preliminarily and 5000-mesh sandpaper after the laser processing. Finally, the processed textured tool is rinsed with absolute ethanol. The photomicrograph is taken with 500 times magnification using a high-speed digital camera (Type: KEYENCE VW-9000).

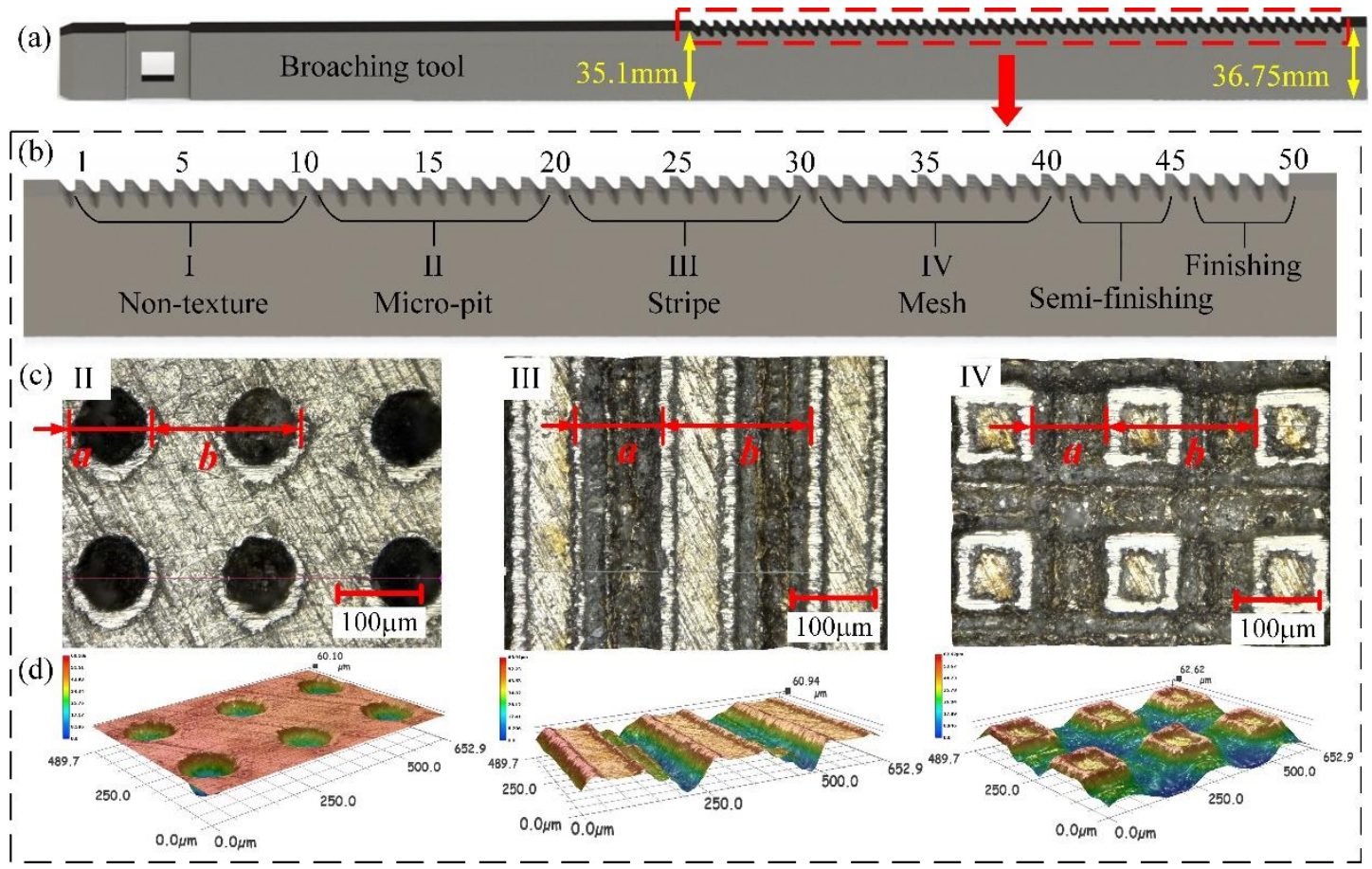

Fig. 3. Broaching tool: (a) schematic diagram of broaching tool, (b) distribution of textures on cutting teeth, (c) different textures, and (d) surface topography of textures.

\subsection{Covering process}

The process of covering copper on the rake face of broaching tool is illustrated in Fig. 4. The material of the copper bar used in this experiment is made of red copper $\mathrm{C} 11000$, whose main components and properties are listed in Table 3. 
Table 3 Main components and properties of red copper C11000

\begin{tabular}{|c|c|c|c|c|c|c|c|}
\hline $\begin{array}{c}\mathrm{Cu}+\mathrm{Ag} \\
\%\end{array}$ & $\begin{array}{l}\mathrm{Bi} \\
\%\end{array}$ & $\begin{array}{l}\mathrm{Sb} \\
\%\end{array}$ & $\begin{array}{l}\text { As } \\
\%\end{array}$ & $\begin{array}{l}\mathrm{Fe} \\
\%\end{array}$ & $\begin{array}{l}\mathrm{Pb} \\
\%\end{array}$ & $\begin{array}{l}\mathrm{S} \\
\%\end{array}$ & $\begin{array}{c}\text { Others } \\
\%\end{array}$ \\
\hline 99.9 & 0.001 & 0.002 & 0.002 & 0.005 & 0.005 & 0.005 & 0.08 \\
\hline \multicolumn{2}{|c|}{ Tensile strength } & \multicolumn{3}{|c|}{ Rockwell hardness } & \multicolumn{3}{|c|}{ Elongation } \\
\hline \multicolumn{2}{|c|}{$\geq 295 \mathrm{MPa}$} & \multicolumn{3}{|c|}{$\geq 65 \mathrm{HRF}$} & \multicolumn{3}{|c|}{$\geq 3 \%$} \\
\hline
\end{tabular}
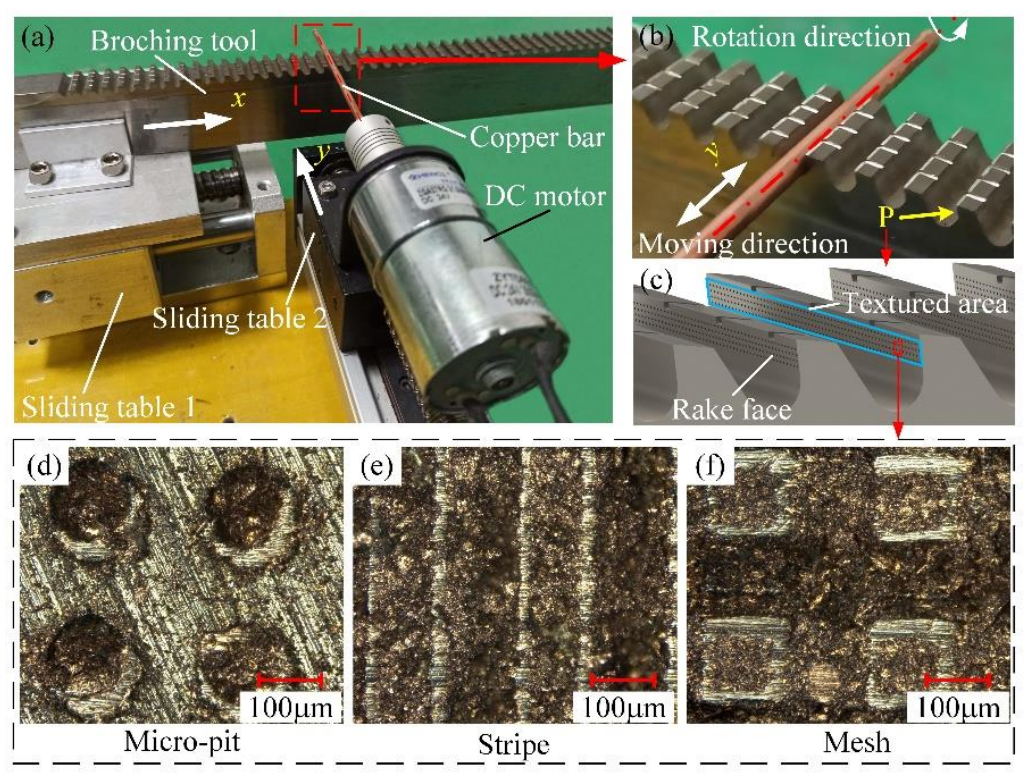

Fig. 4. Process of covering copper on the rake face of broaching tool: (a) device, (b) detailed diagram of reciprocating rotational friction, (c) texture area, (d)-(f) different textures after covering copper.

Automatic equipment is developed for covering the copper, as demonstrated in Fig. 4(a). The broaching tool with different textures is clamped on the fixture of sliding table 1; the feed movement of sliding table 1 is along the $x$-direction. A copper bar is fastened with a DC motor rotor through a flexible coupling, and the DC motor is fixed on the sliding table 2. To cover the copper on the rake face of cutting teeth more evenly, the copper bar rotates while making reciprocating movements with the sliding table 2 in the $y$-direction, as shown in Fig. 4(b). The P direction in Fig. 4(b) is shown in Fig. 4(c), which depicts the position of textures on the rake face of broaching tool. After the copper is evenly grounded into grooves of textures, photomicrographs of textures with copper are taken by a KEYENCE VW-9000 high-speed digital camera with a magnification of 500 times, as shown in Figs. 4(d)-4(f). The cutting teeth with micro-pitted texture with copper, striped texture with copper, meshed texture with copper, and textures with copper are denoted as PT-C, ST-C, MT$\mathrm{C}$, and NT-C, respectively. Detailed processing parameters of the device for covering copper are given in Table 4. 
Table 4 Processing parameters of the device for covering copper

\begin{tabular}{lll}
\hline Unit & Parameter & Value \\
\hline \multirow{2}{*}{ Sliding table 1} & Linear speed $(x)$ & $50 \mathrm{~mm} / \mathrm{s}$ \\
& Stroke & $300 \mathrm{~mm}$ \\
Sliding table 2 & Linear speed $(y)$ & $50 \mathrm{~mm} / \mathrm{s}$ \\
DC motor & Stroke & $100 \mathrm{~mm}$ \\
Single tooth & Rotational speed & $100 \mathrm{rpm}$ \\
\hline
\end{tabular}

\section{Experiment}

Results are discussed in terms of cutting force, chip thickness, and curling radius of the chip. A broaching tool without texture is used as a reference for comparison purposes. As mentioned earlier, repeatability is guaranteed for each experiment.

\subsection{Cutting force}

In order to ensure the reliability of experimental data, each set of tests is carried out five times. The test is firstly performed using the broaching tool without textures; this technique is used as a reference for subsequent tests. To maintain the same working condition for the teeth, surfaces are prepared on the same broaching tool; broaching tests are conducted under a unified working condition. Afterward, copper is covered on the textured tool, and broaching tests are carried out again. Working conditions to be consistent, copper is covered again by the equipment after each broaching test. The effect of different textures and copper on the cutting performance of broaching tool is investigated as follows. The maximum cutting force of each tooth is chosen based on broaching test data; the average value of maximum cutting force corresponding to each texture is then calculated.

As shown in Fig. 5, after the fabrication of textures, the cutting force (blue bar) decreases dramatically compared with that of the non-textured broaching tool. The cutting force of ST (III) has the most significantly reduced value, which amounted to $86.7 \mathrm{~N}(7.6 \%)$. The cutting force of PT (II) is reduced by $60.4 \mathrm{~N}(5.4 \%)$. The cutting force of MT (IV) has a minor reduction, equivalent to $32.6 \mathrm{~N}(2.8 \%)$.

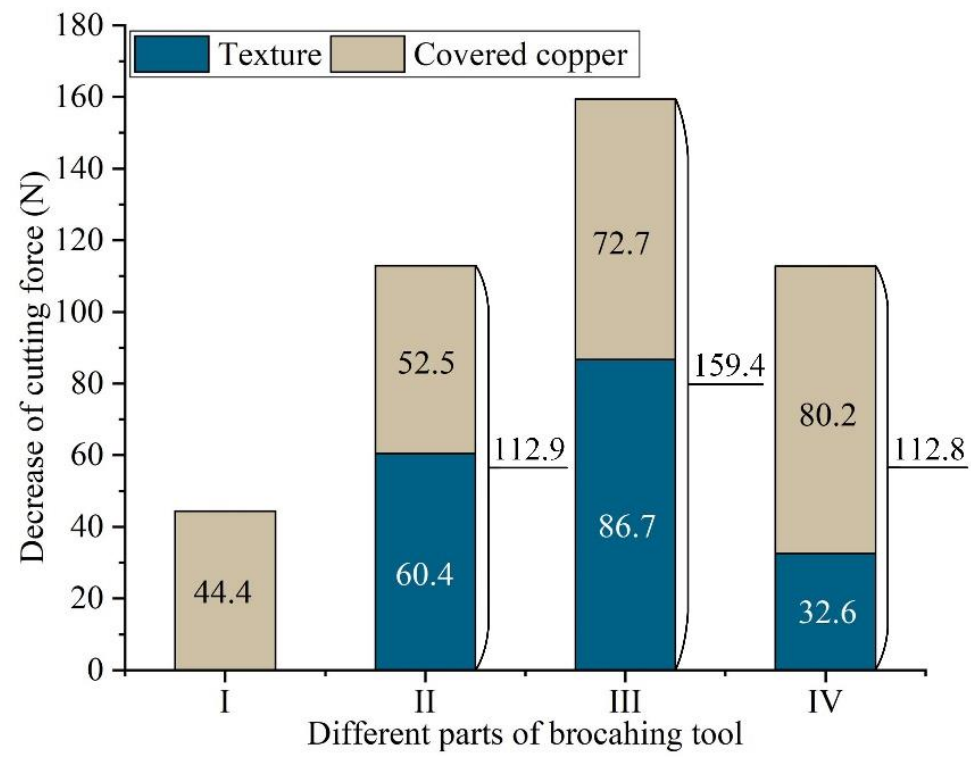

Fig. 5. Decrease in cutting force under different conditions. 
After covering the copper on the rake face of the broaching tool, the downward trend of cutting force exhibits some changes compared with that of the textured tool. The most significant reduction in the cutting force can be ascribed to MT-C, which is $80.2 \mathrm{~N}(7.2 \%)$. The cutting force for ST-C is decreased by $72.7 \mathrm{~N}$ (7\%), followed by PT-C, whose cutting force is reduced by $52.5 \mathrm{~N}(5 \%)$. The minor reduction of cutting force is for NT-C, representing 44.4N (3.9\%).

According to the above analysis, the cutting force of copper-covered tool is compared with that of the non-textured tool. The cutting force of ST-C decreases by $14.1 \%$; minor differences in reducing cutting forces between PT-C and MT-C exist, reduced by $10 \%$ and $9.8 \%$, respectively.

\subsection{Chip thickness}

Chips in three parts of the broaching tool are collected after broaching. The middle section of the chip (stable cutting area) is selected as the research object. Photos are taken using the high-speed digital camera at a magnification of 1000 times, as shown in Fig. 6. The average of five measurements at equal intervals is calculated as follows:

$$
d=\frac{\left(d_{1}+d_{2}+d_{3}+d_{4}+d_{5}\right)}{5}
$$

where $d$ is the average value of chip thickness, $d_{1}-d_{5}$ are measured values of the chip thickness at five positions, respectively.

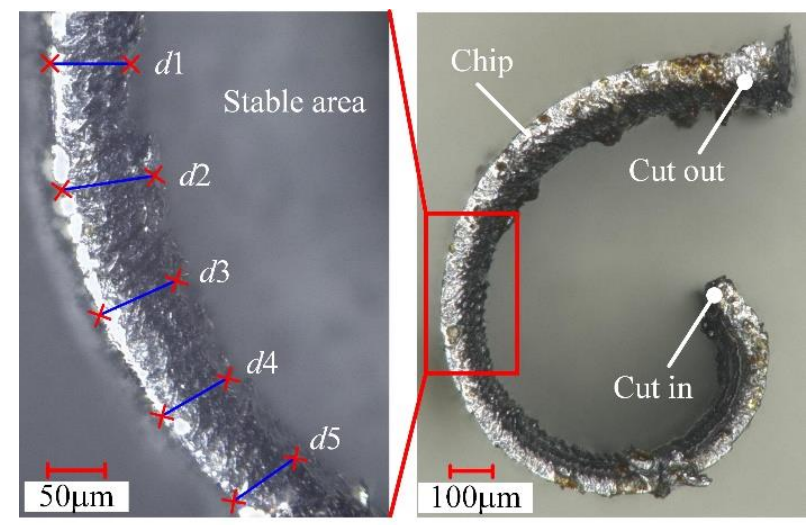

Fig. 6. Photo of the chip after broaching.

The variation in chip thickness under different working conditions is described in Fig. 7. NT generates the most significant chip thickness, which equals $90.2 \mu \mathrm{m}$. The most negligible chip thickness, $64.1 \mu \mathrm{m}$, is produced by ST. The chip thickness of PT is $77.6 \mu \mathrm{m}$, which is smaller than that of MT (i.e., $86.7 \mu \mathrm{m})$.

When the copper-coated teeth are used for testing, the variation in chip thickness differs from the non-coated textured tool. The most negligible chip thickness, $57.2 \mu \mathrm{m}$, comes from ST-C. NT-C obtains the thickest $80.1 \mu \mathrm{m}$ chip. Chip thicknesses of PT-C and MT-C are similar; they are $72.1 \mu \mathrm{m}$ and $72.2 \mu \mathrm{m}$, respectively. 


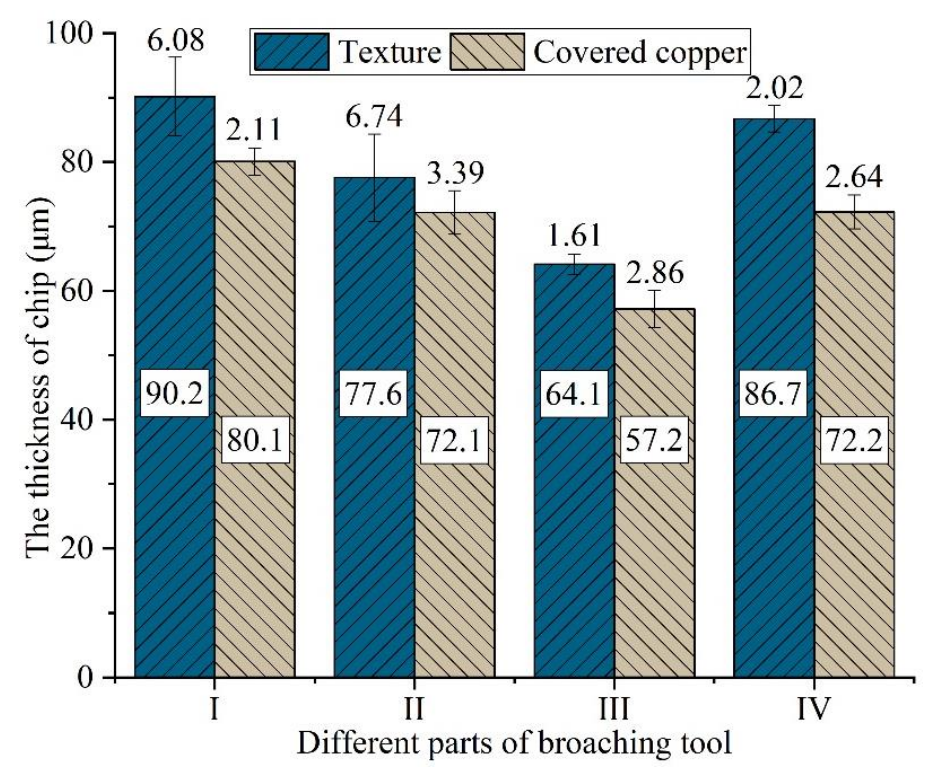

Fig. 7. Chip thicknesses under different working conditions.

\subsection{Curling radius of chip}

Photomicrographs of the chip are taken using a high-speed digital camera at a magnification of 20 times, as displayed in Fig. 8. The curling radius of a chip on three different positions is measured to describe various working conditions' influence accurately. A rectangular coordinate system is established. The initial point $\mathrm{A}$ and the highest point $\mathrm{B}$ of the chip pass through the $x$-axis and $y$-axis, respectively, and the cut-in part of the chip is perpendicular to the $x$-axis. The chip and the coordinate system intersect at three points $\mathrm{B}, \mathrm{C}$, and $\mathrm{D}$, respectively; $\mathrm{p} 1, \mathrm{p} 2$, and $\mathrm{p} 3$ denote tangents on these three points. The origin of coordinates is the center of circle $1\left(\mathrm{O}_{1}\right)$, and $\mathrm{O}_{1} \mathrm{~B}$ is the radius. The center of circle $2\left(\mathrm{O}_{2}\right)$ is on a line perpendicular to $\mathrm{p}_{2}$, and circle 2 is circumscribed to circle 1 . Similarly, circle 3 is circumscribed to circle 2 , and the center of circle $3\left(\mathrm{O}_{3}\right)$ lies on a line perpendicular to $\mathrm{p}_{3}$.

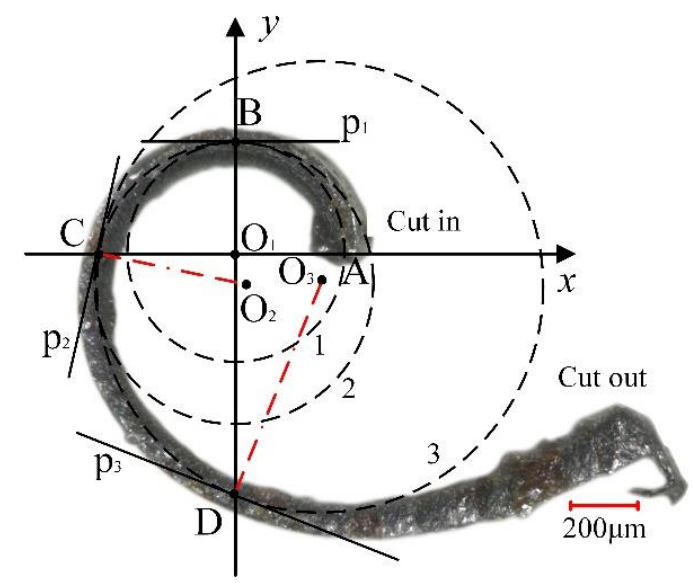

Fig. 8. Evaluation of curling radius of the chip.

The curling radius of chips on three positions under each working condition is measured and demonstrated in Fig. 9. As shown in Fig. 9(a), lengths of O1B, O2C, and O3D reflect the influence of different textures on the curling radius with consistent changing trends. The smallest curling radius of the chip occurs in ST; NT has the largest curling radius of the chip. Lengths of the curling radius of the chip are sorted from large to undersized as NT, MT, PT, and ST. It proves that textures 
on the tool surface reduce the curling radius of the chip. The curling radius of chips using the coppercoated tool is illustrated in Fig. 9(b). The largest curling radius of the chip is obtained by NT-C, followed by PT-C, MT-C, and ST-C. The data mentioned above show that the curling radius of chips is reduced because of the copper covering, which is enhanced more for the meshed texture.
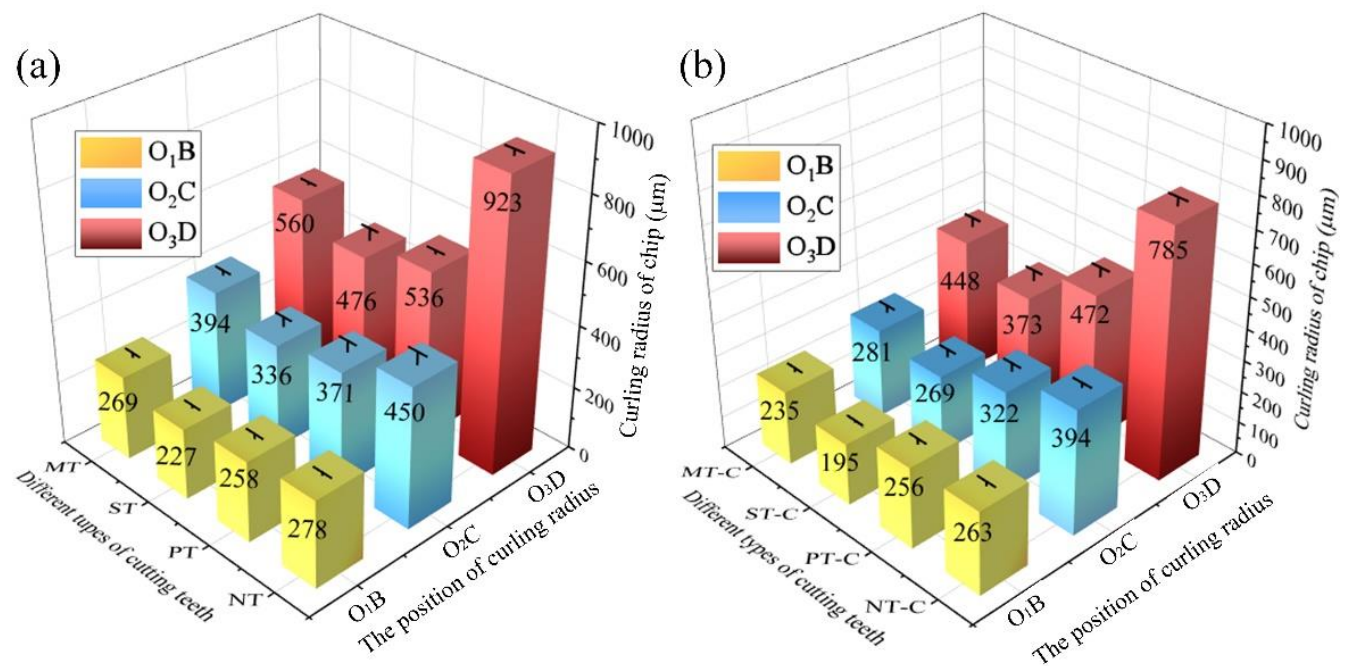

Fig. 9. Curling radius of chip: (a) textured tool and (b) copper-coated textured tool.

\section{Discussions}

\subsection{Mechanism of the texture}

In the metal cutting process, chips are formed by the extrusion and shearing of the tool. Bai et al. (2020) proved that the contact and friction of the tool-chip interface directly affect the deformation of the material, cutting temperature, the surface quality of the workpiece, and cutting force. Based on the research of Hwang (2014), the contact area between the chip and the tool is divided into bonding zone $l_{1}$ and slip zone $l_{2}$. The forming of the chip in the cutting process is demonstrated in Fig. 10.

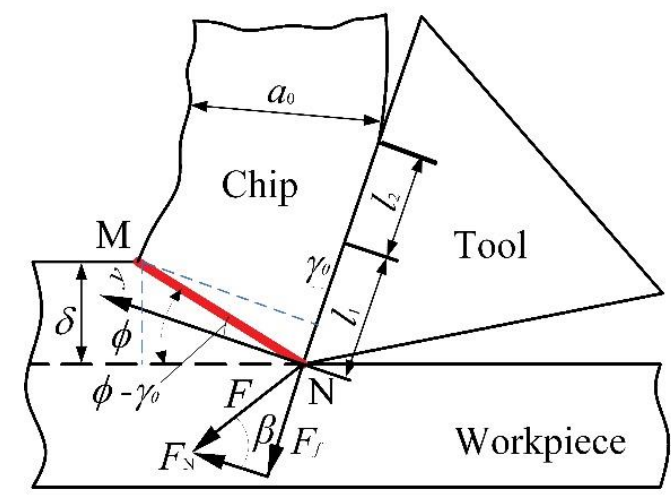

Fig. 10. Forming of chip in the cutting process.

Fang (2014) reported that the frictional force and positive pressure on the tool-chip interface are the main sources of cutting force during the cutting process. The relationship between them can be given according to Shaw (1984) as: 


$$
\tan \beta=\frac{F_{f}}{F_{N}}
$$

where $F_{f}$ is the frictional force, $F_{N}$ is positive pressure, and $\beta$ is the frictional angle.

Textures on the tool surface do not significantly change the positive pressure. Therefore, $F_{N}$ is regarded as a fixed value in this condition and will not be discussed. According to the investigation of Zhang et al. (2015), $F_{f}$ mainly comes from the shearing of materials and lubricants and can be expressed by:

$$
F_{f}=\tau_{s} A_{s}+\tau_{l} A_{l}
$$

where $\tau_{s}$ is the shear yield stress of the material, $A_{s}$ is the bonding area of the tool-chip interface, $\tau_{l}$ is the shear strength of lubricant, and $A_{l}$ is the penetration area of lubricant.

Compared with non-textured cutting teeth, the $A_{s}$ of textured cutting teeth is significantly reduced. $F_{f}$ in turn, decreases according to Equation (3) and $\beta$ also becomes lower according to Equation (2).

According to the research of Lee and Shaffer (1951), the shear angle $\phi$ is given by:

$$
\varphi=\frac{\pi}{4}-\beta+\gamma_{0}
$$

where $\gamma_{0}$ is the rake angle of the cutting tooth, which is a fixed value. To investigate the deformation of the chip, the following relation is introduced by Shaw (1984):

$$
\xi=\frac{a_{0}}{\delta}=\frac{M N \cdot \cos \left(\phi-\gamma_{0}\right)}{M N \cdot \sin \phi}=\frac{\cos \left(\phi-\gamma_{0}\right)}{\sin \phi}
$$

where $\xi$ is the chip deformation coefficient, $a_{o}$ is the deformed chip thickness (actual measured value), $\delta$ is the undeformed chip thickness, and MN is the shear band. According to the above equations, the relationship between $a_{o}$ and $A_{s}$ is finally deduced.

The mechanism of different textures in the cutting process is illustrated in Fig. 11, where the area ratios $S$ for each surface are calculated based on the following relation:

$$
S=\frac{A_{\text {texture }}}{A_{\text {unit }}}
$$

where $A_{\text {texture }}$ is the area of texture per unit area, and $A_{\text {unit }}$ is the unit area; values of $S$ for mesh, stripe, and micro-pit textures are calculated as $64 \%, 40 \%$, and $12.6 \%$, respectively.

In the bonding zone, interface materials bond to each other due to higher stress, as shown in Fig. 11(a). Fig. 11(b) and Fig. 11(c) demonstrate that S's value on ST is greater than that of PT. An increase in $S$ reduces the area of the bonding zone, thereby reducing the cutting force. As exhibited in Fig. 11(d), the maximum value of $S$ happens to be imposed on MT when the workpiece material is easily pressed into grooves of the meshed texture due to lack of support. This results in a significant increase in the bonding zone and the cutting force. Therefore, the cutting force of MT does not decrease with an increase in $S$. 

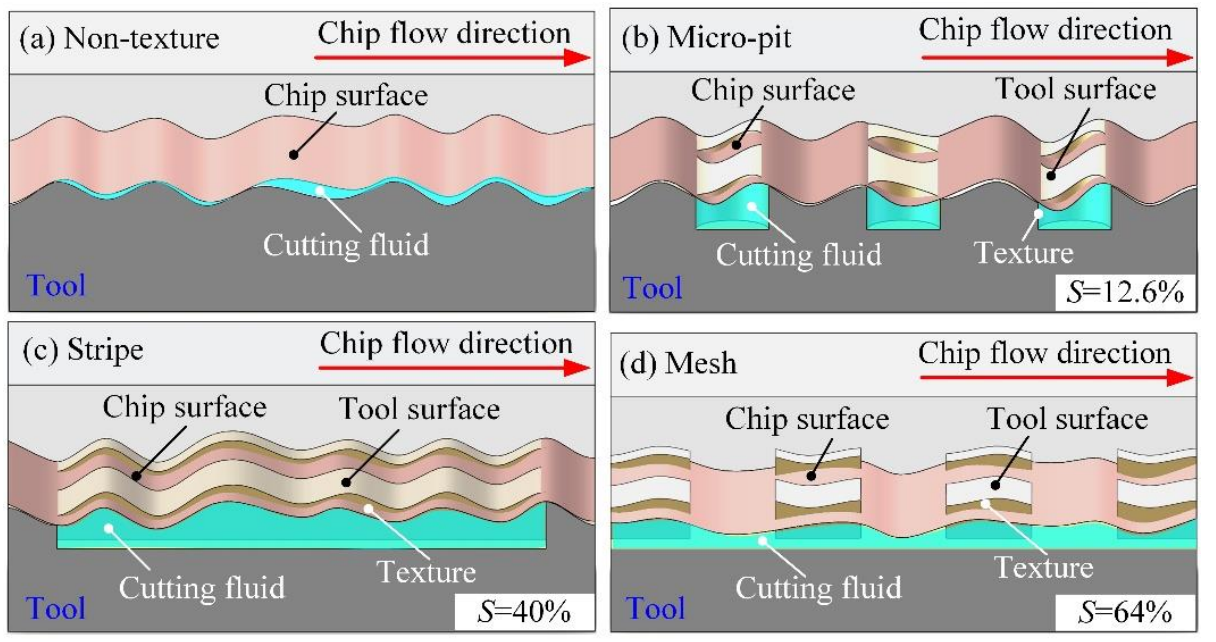

Fig. 11. Influence of different textures on cutting force.

The actual shear band is a convex curved surface, as demonstrated in Fig. 12. The shear angle $\phi_{1}$ at the bottom layer of the chip is greater than the shear angle $\phi_{2}$ at the upper layer. Based on Equation (5), the larger the $\phi$ is, the smaller the $\xi$ will be. According to Shaw (1984), the relationship between the speed of chip and $\xi$ can be calculated as:

$$
v_{c}=\frac{\sin \varphi}{\cos \left(\varphi-\gamma_{0}\right)} \cdot v=\frac{v}{\xi}
$$

where $v_{c}$ is the speed of the chip and $v$ is the cutting speed. In fact, $v$ is considered as a constant during the cutting process; therefore, $v_{c}$ is inversely proportional to $\xi$. The cutting speed at the bottom of the chip equals the upper layer $\left(v_{1}=v_{2}\right)$. A speed vector triangle can be drawn according to the sliding direction and shear angles of the chip on the bottom and upper layers. Among them, $v_{s 1}$ and $v_{s 2}$ are parallel to the tangent of shear-plane bottom and upper layers, respectively. The flow speed of the bottom metal of the chip is greater than that of the upper layer $\left(v_{\mathrm{cl}}>v_{\mathrm{c} 2}\right)$, causing the chip to curl upward. The curling radius of the chip is inconsistent in different parts of the broaching tool. One possible reason is that textures on the tool surface reduce $\xi$ such that the relative flow speed between the bottom and upper metal of the chip is different. The curling radius of the chip is compatible with the changing trend of cutting force discussed earlier.

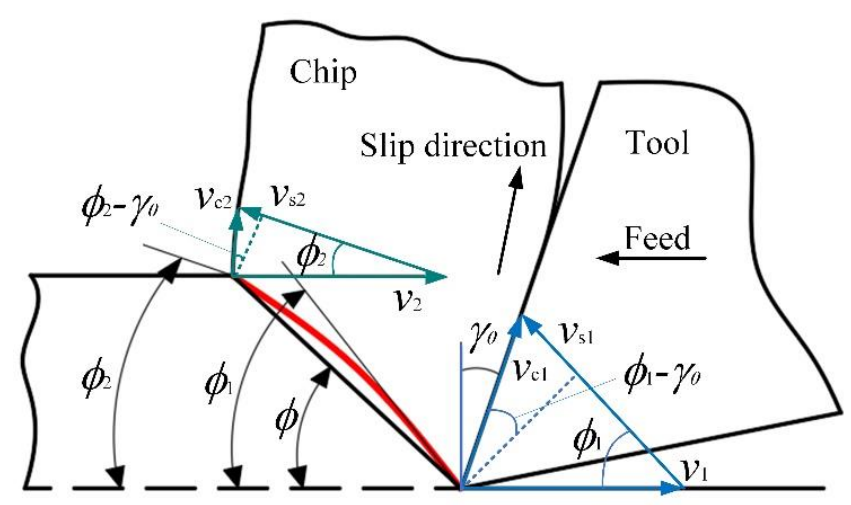

Fig. 12. Curling of chip in the cutting process.

\subsection{Influence of copper covering on cutting performance}

Chips are in close contact with the tool's rake face during the cutting process, especially at the bonding area $\left(l_{1}\right)$, as depicted in Fig. 13(a). The existence of texture on the tool surface allows the 
cutting fluid to be stored, and hence, a lubricating oil film is formed in the cutting area, as displayed in Fig. 13(b). Because of a lower hardness, copper is used as the solid lubricant for the textured tool surface. The low-hardness copper forms a solid lubricating film during the cutting process without causing scratches and wearing on the tool surface, as demonstrated in Fig. 13(c). After covering copper in the groove textures, there are gaps between the chip and the tool surface due to the support of copper debris. The existence of these gaps assists the cutting fluid to penetrate more into the slit of the tooltip. Therefore, copper covering reduces the bonding area between chip and tool, and increases the thickness of the lubricating film, leading to a reduction in the cutting force.
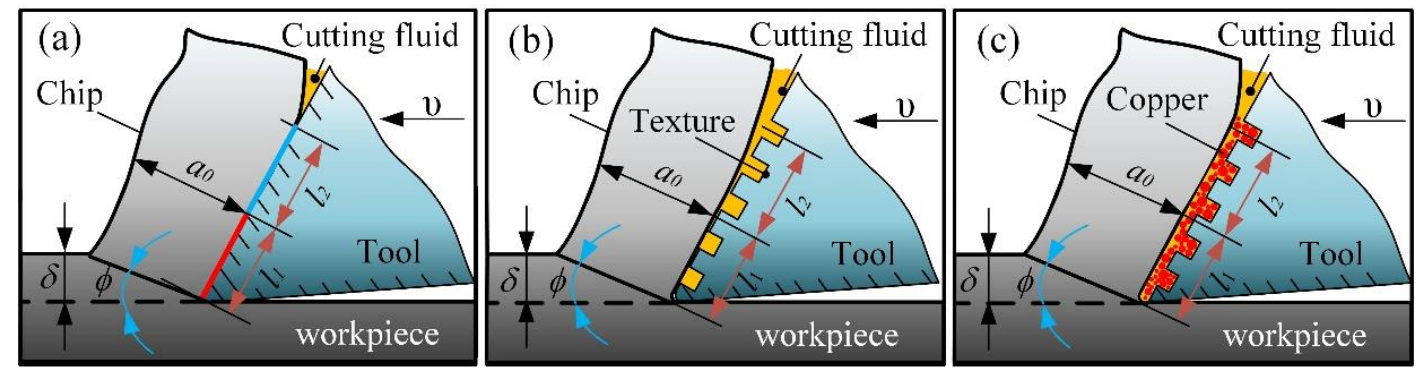

Fig. 13. Cutting process: (a) non-textured tool, (b) textured tool and (c) copper-coated tool.

To further investigate the influence of textures and copper covering the wetting performance of the tool, six sets of surfaces are prepared on the specimen of steel HSS-6542. The spacing and size are the same as the non-textured cutting tooth; three sets of textured tools are coated with copper using the same method of reciprocating rotational friction. The contact angle $(\alpha)$ of the cutting fluid on each specimen is measured by contact angle meter (TYPE: POWER EACH JC2000D1). The droplet volume for each wettability test is $5 \mu \mathrm{L}$. The contact angle is evaluated when the droplet falls on the specimen for 8s (namely the steady-state). Even further, a high-speed camera is used to take a snapshot of the droplet, shown in Fig. 14.

Textures on the tool surface store the cutting fluid and generate micro-pool lubrication. However, according to the Cassie model proved by Cassie and Baxter (1944), the presence of texture generates an air cushion in the groove of the tool surface, thereby reducing the wettability of the cutting fluid at the tool-chip interface. The contact angle of the surface with different textures is shown in Fig. 14. The slightest contact angle $53^{\circ}$ occurs on the specimen without consistency, which means that the cutting fluid has an affinity for the material's surface. The most significant contact angle occurs on the striped texture, which is $66.5^{\circ}$. Its length along the longitudinal direction of texture is also the largest, i.e., $4565 \mu \mathrm{m}$. This is because grooves formed by the striped surface hinder the horizontal spreading of cutting fluid, and the longitudinal grooves have a drainage effect as a channel to make the cutting fluid spread quickly. Longitudinal lengths of micro-pitted and meshed textures are similar, which are $3206 \mu \mathrm{m}$ and $3405 \mu \mathrm{m}$, respectively, and much smaller than those of striped textures. Since the cutting fluid on the striped texture flows faster in the longitudinal direction, the tool surface is wetted rapidly during the cutting process. Therefore, the lubrication of the tool-chip interface is greatly improved. 


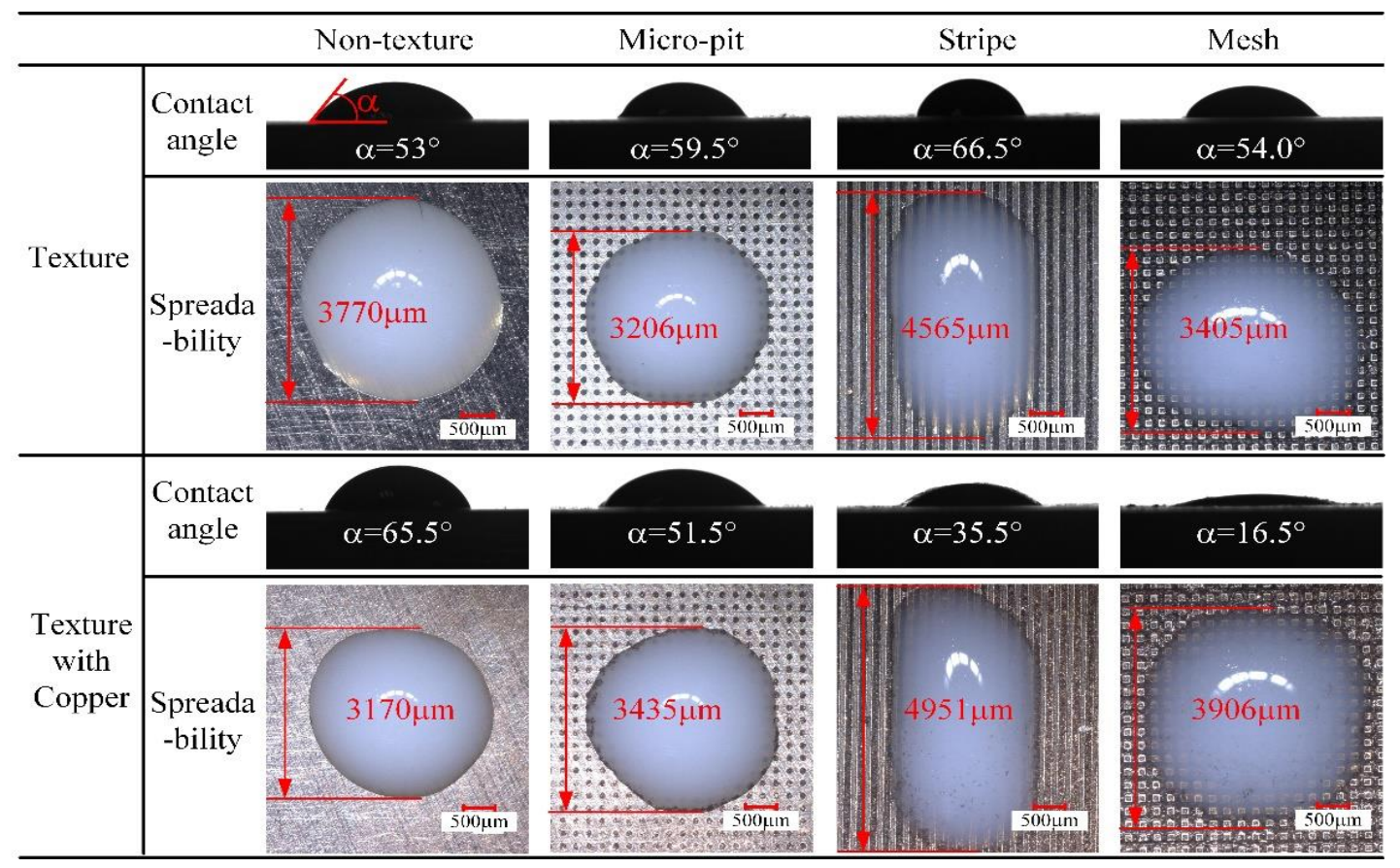

Fig. 14. Wettability of different textures with copper covering.

After the textures are processed by the copper bar, grooves of the texture are covered by tiny copper debris. According to Wenzel's model (1936), the specimen's surface is generally flat, and the specimen's grooves are filled with liquid. It can be seen from Fig. 14 that contact angles and longitudinal lengths of all textures with copper covering are improved. Remarkably, contact angle of the meshed surface is reduced from $54^{\circ}$ to $16.5^{\circ}$, while its longitudinal length is increased by 501 $\mu \mathrm{m}$ (from $3405 \mu \mathrm{m}$ to $3906 \mu \mathrm{m}$ ). Since the copper in the textured groove forms many loose micropores, the generated capillary force makes droplets spread rapidly on the surface. The lubrication condition of machining is enhanced as the surface wettability improved, and the cutting force is reduced accordingly. Therefore, the cutting force of MT is significantly reduced, and the striped texture still has a good performance in the longitudinal spreading.

As illustrated in Fig.15(a), the tool's surface has a wavy surface profile with unevenness in the microscopic view. As a soft metal, copper fills the dimples on the tool surface during the rotating frictional process and blunts the prominent convex peaks. It reduces the shear force and friction generated by the relative movement of material and tool. This is also the reason for reducing the cutting force for non-textured cutting teeth after being coated with copper. 

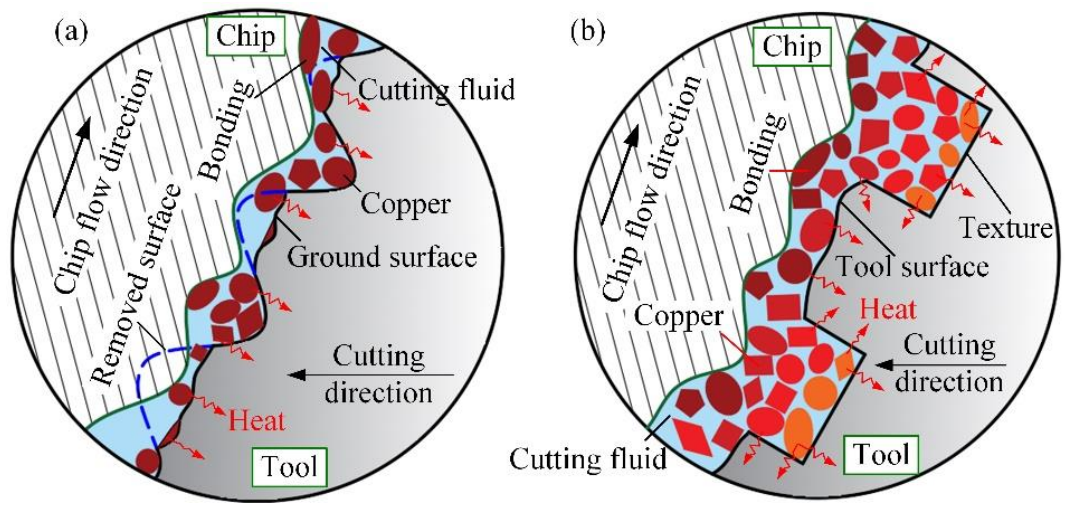

Fig. 15. Mechanism of tooltip slit after copper covering: (a) non-textured surface and (b) textured surface.

Figure 15(b) indicates that a large amount of copper debris act as a solid lubricant in the cutting area. The relative violent friction between the chip and the tool generates a lot of heat because of the heavy load in broaching. The copper debris in the cutting area quickly absorbs the heat because of its excellent thermal conductivity. Some copper debris with high temperatures adhere to the chips and are taken away with the flow of chips. The rest are either washed away by the cutting fluid or squeezed into the textured groove. Textures increase the surface area of the tool surface, and heat dissipation rises accordingly. Consequently, copper debris accelerates the heat transfer efficiency in the groove and lowers the temperature of the tool surface. A decrease in temperature makes it difficult for the workpiece material to accumulate and bond at the tooltip; thereby, the shear force generated by material bonding is reduced, and so is the cutting force. Moreover, the copper covering changes the frictional force of the tool-chip interface and affects the frictional and shear angles when chips are generated.

\section{Conclusion}

The research outcome of this paper can be summarized as follows:

- Textures on the tool surface decrease the contact area of the tool-chip interface and reduce the cutting force. The striped texture has an excellent spread-ability in the longitudinal direction, and therefore, the cutting force of the tool with striped texture is the smallest.

- Textured tool decreases the chip thickness, curling radius, and friction of the tool surface. This is due to the reduction in chip deformation coefficient and an increase in the shear angle.

- Convex peaks on the tool surface are passivated during the reciprocating rotation of the copper bar; thereby, the shearing force caused by convex peaks on the surface of the tool and chips is reduced. Simultaneously, copper debris is filled in the textures as the solid lubricant and decreases the cutting force.

- A large number of micro-pores are generated in the groove of copper-coated textures. The capillary force formed by these micro-pores improves the wettability of the tool surface. In addition, copper debris with high temperature stick to the chips and is removed from the tool surface with the chip slide.

\section{Authors' contribution statement}

Jing Ni: Supervision and guidance; Kai Feng: Experiment and writing-original draft; Kai Zhuang: Investigation and formal analysis; Zhiqian Sang: Revision; Zhen Meng: Formal analysis; Md 
Mizanur Rahman: Critical analysis, suggestion and revision.

\section{Declaration of Compelling Interest}

The authors declare that no conflict of interest exists.

\section{Acknowledgments}

National Natural Science Foundation of China (Grant No. 51775153) and Science Foundation for Distinguished Young Scholars of Zhejiang, China (Grant No. LR20E050002) have supported this research.

\section{Reference}

Ahmed, Y.S., Paiva, J.M., Arif, A.F.M., Amorim, F.L., Torres, R.D., Veldhuis, S.C., 2020. The effect of laser micro-scale textured tools on the tool-chip interface performance and surface integrity during austenitic stainless-steel turning. Appl. Surf. Sci. 510, 145455, https://doi.org/10.1016/j.apsusc.2020.145455.

Arrazola, P.J., Rech, J., M'Saoubi, R., Axinte, D., 2020. Broaching: Cutting tools and machine tools for manufacturing high features in components. CIRP Ann-manuf. Tech. 69, 554-577, https://doi.org/10.1016/j.cirp.2020.05.010.

Bai, W., Roy, A., Guo, L., Xu, J., Silberschmidt, V.V., 2020. Analytical prediction of shear angle and frictional behaviour in vibration-assisted cutting. J. Manuf. Process. 62, 37-46, https://doi.org/10.1016/j.jmapro.2020.12.026.

Cassie, A.B.D. Baxter, S., 1944. Wettability of porous surfaces. T. Faraday Soc. 40, 546-551, https://doi.org/10.1039/tf9444000546

Deng, J., Lian, Y., Wu, Z., Xing, Y., 2013. Performance of femtosecond laser-textured cutting tools deposited with $\mathrm{WS}_{2}$ solid lubricant coatings. Surf. Coat. Tech. 222, 135-143, http://dx.doi.org/10.1016/j.surfcoat.2013.02.015.

Deng, J., Wu, Z., Lian, Y., Qi, T., Cheng, J., 2012. Performance of carbide tools with textured rakeface filled with solid lubricants in dry cutting processes. Int. J. Refract. Met. H. 30, 164-172, http://doi.org/10.1016/j.ijrmhm.2011.08.002.

Enomoto, T., Sugihara, T., 2010. Improving anti-adhesive properties of cutting tool surfaces by nano-/micro-textures. CIRP Ann-manuf. Techn. 59, 597-600, https://doi.org/10.1016/j.cirp.2010.03.130.

Enomoto, T., Sugihara, T., 2011. Improvement of anti-adhesive properties of cutting tool by nano/micro textures and its mechanism. Procedia Eng. 19, 100-105, https://doi.org/10.1016/j.proeng.2011.11.086.

Feng, Y., Zhang, J., Wang, L., Zhang, W., Dong, Y., 2019. Study on secondary cutting phenomenon of micro-textured self-lubricating ceramic cutting tools with different morphology parameters formed via in situ forming of Al2O3-TiC. Int. J. Adv. Manuf. Tech. 104, 3821-3833, https://doi.org/10.1007/s00170-019-04045-x.

Fang, N., 2005. Tool-chip friction in machining with a large negative rake angle tool. Wear 258, 90897, https://doi.org/10.1016/j.wear.2004.09.047.

Ge, D., Deng, J., Duan, R., Liu, Y., Li, X., Yue, H., 2019. Effect of micro-textures on cutting fluid lubrication of cemented carbide tools. Int. J. Adv. Manuf. Tech. 103, 3887-3899, https://doi.org/10.1007/s00170-019-03763-6.

Hwang, J., 2014. Direct observation of fluid action at the chip -tool interface in machining. Int. J. 
Precis. Eng. Man. 15, 2041-2049, https://doi.org/10.1007/s12541-014-0561-0.

Koshy, P., Tovey, J., 2011. Performance of electrical discharge textured cutting tools. CIRP Annmanuf. Techn. 60, 153-156, https://doi.org/10.1016/j.cirp.2011.03.104.

Kümmel, J., Braun, D., Gibmeier, J., Schneider, J., Greiner, C., Schulze, V., Wanner, A., 2015.

Study on micro texturing of uncoated cemented carbide cutting tools for wear improvement and built-up edge stabilization. J. Mater. Process. Tech. 215, 62-70, http://dx.doi.org/10.1016/j.jmatprotec.2014.07.032.

Lee, E.H., Shaffer, B.W., 1951. The theory of plasticity applied to a problem of machining. J. Appl. Mech-T. ASME 18, 405-413, https://doi.org/10.1007/BF00412000.

Mashinini, P.M., Soni, H., Gupta, K., 2020. Investigation on dry machining of stainless steel 316 using textured tungsten carbide tools. Mater. Res. Express. 7, 016502, https://doi.org/10.1088/2053-1591/ab5630.

Meng, X., Zhang, K., Guo, X., Wang, C., Sun, L., 2021. Preparation of micro-textures on cemented carbide substrate surface by plasma-assisted laser machining to enhance the PVD tool coatings adhesion. J. Mater. Process. Tech. 288, 116870, https://doi.org/10.1016/j.jmatprotec.2020.116870.

Moshkovith, A., Perfiliev, V., Gindin, D., Parkansky, N., Boxman, R., Rapoport, L., 2007. Surface texturing using pulsed air arc treatment. Wear 263, 1467-1469, https://doi.org/10.1016/j.wear.2006.11.043.

Ni, J., Feng, K., He, L., Liu, X., Meng, Z., 2020. Assessment of water-based cutting fluids with green additives in broaching. Friction 8, 1051-1062, https://doi.org/10.1007/s40544-019-0318y.

Niketh, S., Samuel G.L., 2017. Surface texturing for tribology enhancement and its application on drill tool for the sustainable machining of titanium alloy. J. Clean. Prod. 167, 253-270, https://doi.org/10.1016/j.jclepro.2017.08.178.

Obikawa, T., Kamio, A., Takaoka, H., Osada, A., 2011. Micro-texture at the coated tool face for high performance cutting. Int. J. Mach. Tool Manu. 51, 966-972, https://doi.org/10.1016/j.ijmachtools.2011.08.013.

Rao, C.M. Rao, S.S. Herbert, M. A., 2018. Development of novel cutting tool with a micro-hole pattern on PCD insert in machining of titanium alloy. J. Manuf. Process. 36, 93-103, https://doi.org/10.1016/j.jmapro.2018.09.028.

Shaw, M.C., 1984. Metal cutting principles, New York: Oxford University Press.

Voevodin, A.A., Zabinski, J.S., 2006. Laser surface texturing for adaptive solid lubrication. Wear 261, 1285-1292, http://doi.org/10.1016/j.wear.2006.03.013.

Wenzel, R.N., 1936. Resistance of solid surfaces to wetting by water. Ind. Eng. Chem. 28, 988-994, https://doi.org/10.1021/ie50320a024.

Zhang, K., Deng, J., Guo, X., Sun, L., Lei, S., 2018. Study on the adhesion and tribological behavior of PVD TiAlN coatings with a multi-scale textured substrate surface. Int. J. Refract. Metals Hard Mater. 72, 292-305, https://doi.org/10.1016/j.ijrmhm.2018.01.003.

Zhang, K., Deng, J., Xing, Y., Li, S., Gao, H., 2015. Effect of microscale texture on cutting performance of WC/Co-based TiAlN coated tools under different lubrication conditions. Appl. Surf. Sci. 326, 107-118, http://dx.doi.org/doi:10.1016/j.apsusc.2014.11.059.

Zhang, X., Kumar, A.S., Rahman, M., Nath, C., Liu, K., 2011. Experimental study on ultrasonic elliptical vibration cutting of hardened steel Using PCD tools. J. Mater. Process. Tech. 211, 
1701-1709, https://doi.org/10.1016/j.jmatprotec.2011.05.015.

Zhou, C., Guo, X., Zhang, K., Cheng, L., Wu, Y., 2019. The coupling effect of micro-groove textures and nanofluids on cutting performance of uncoated cemented carbide tools in milling Ti-6Al-4V. J. Mater. Process. Tech. 271, 36-45, https://doi.org/10.1016/j.jmatprotec.2019.03.021. 


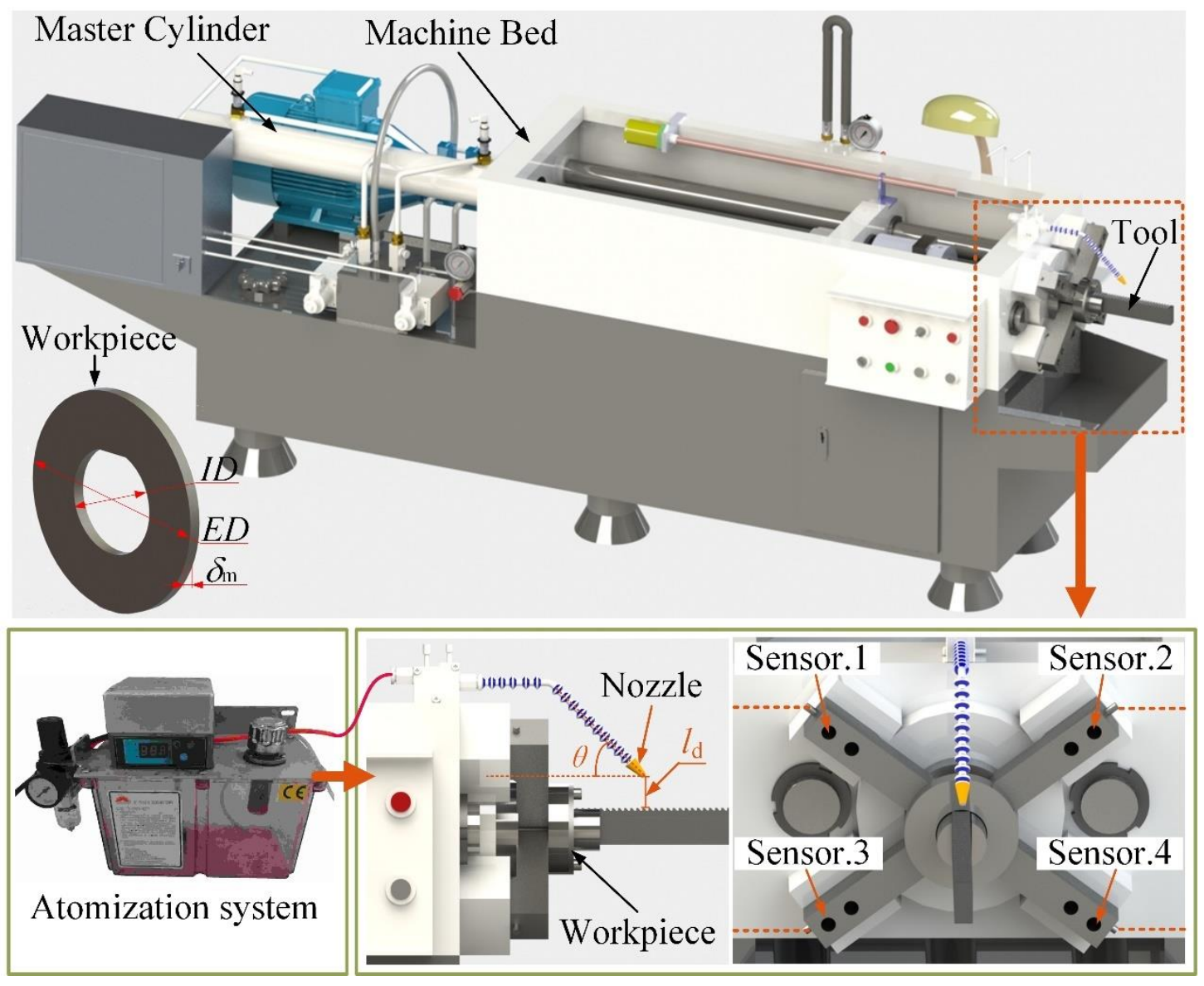




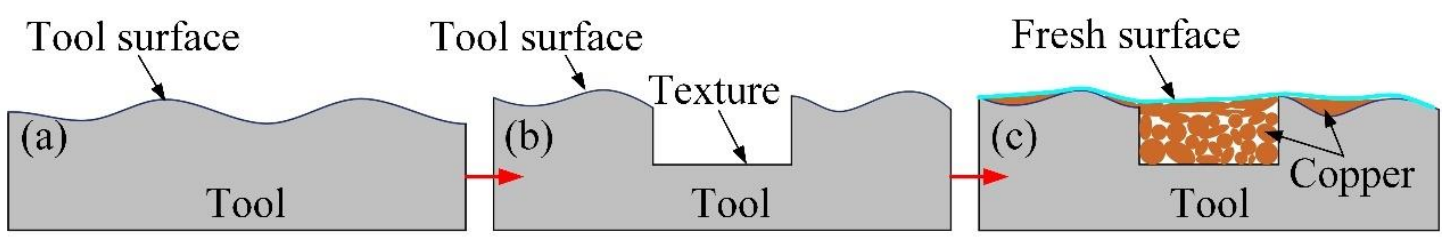



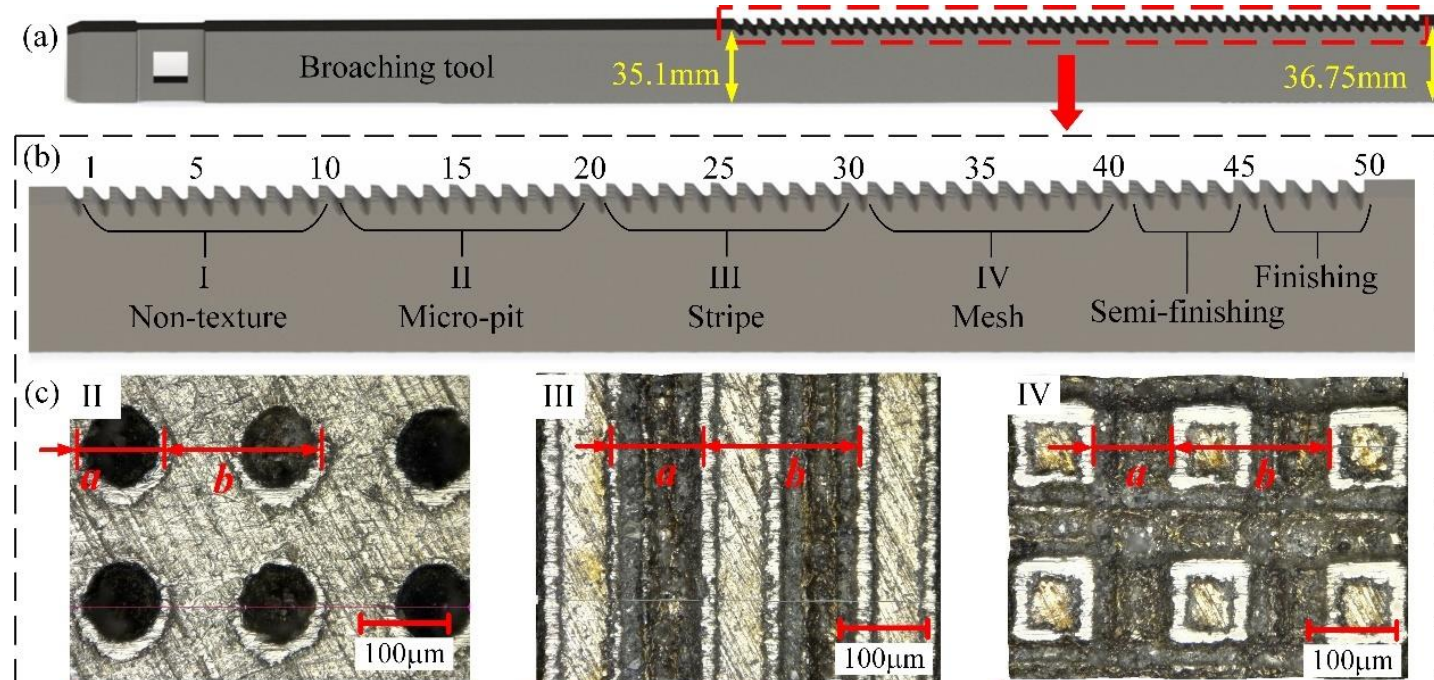


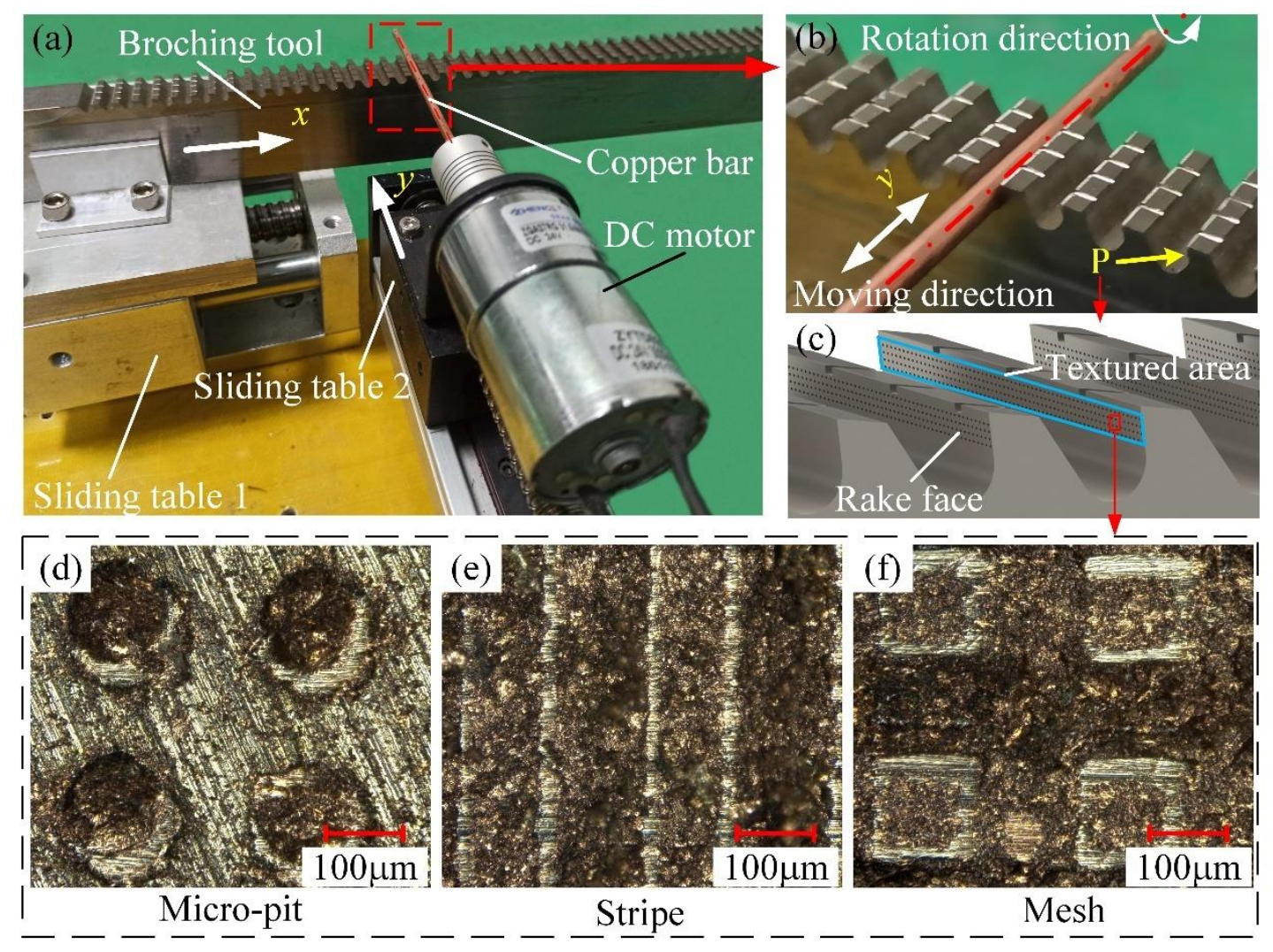




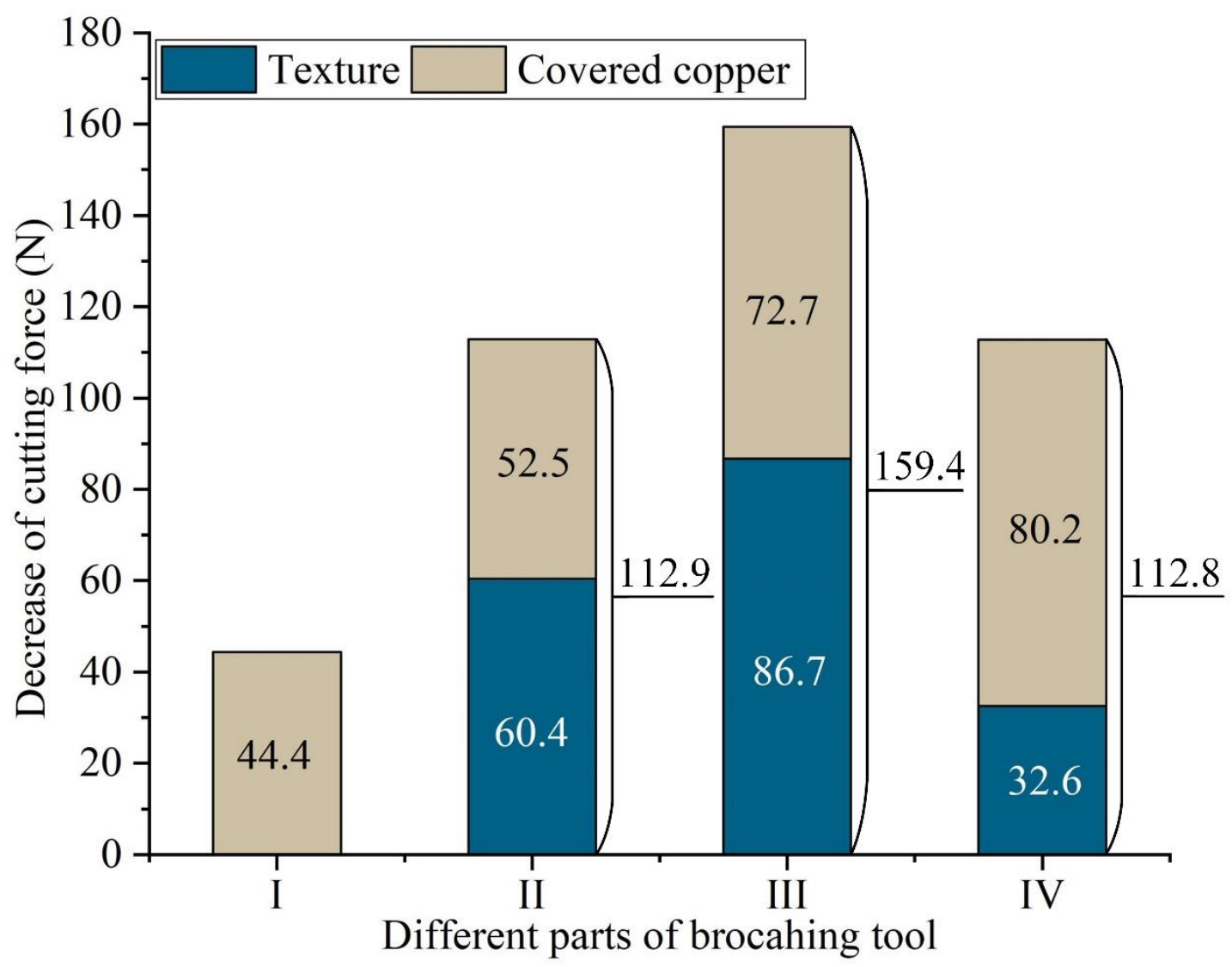




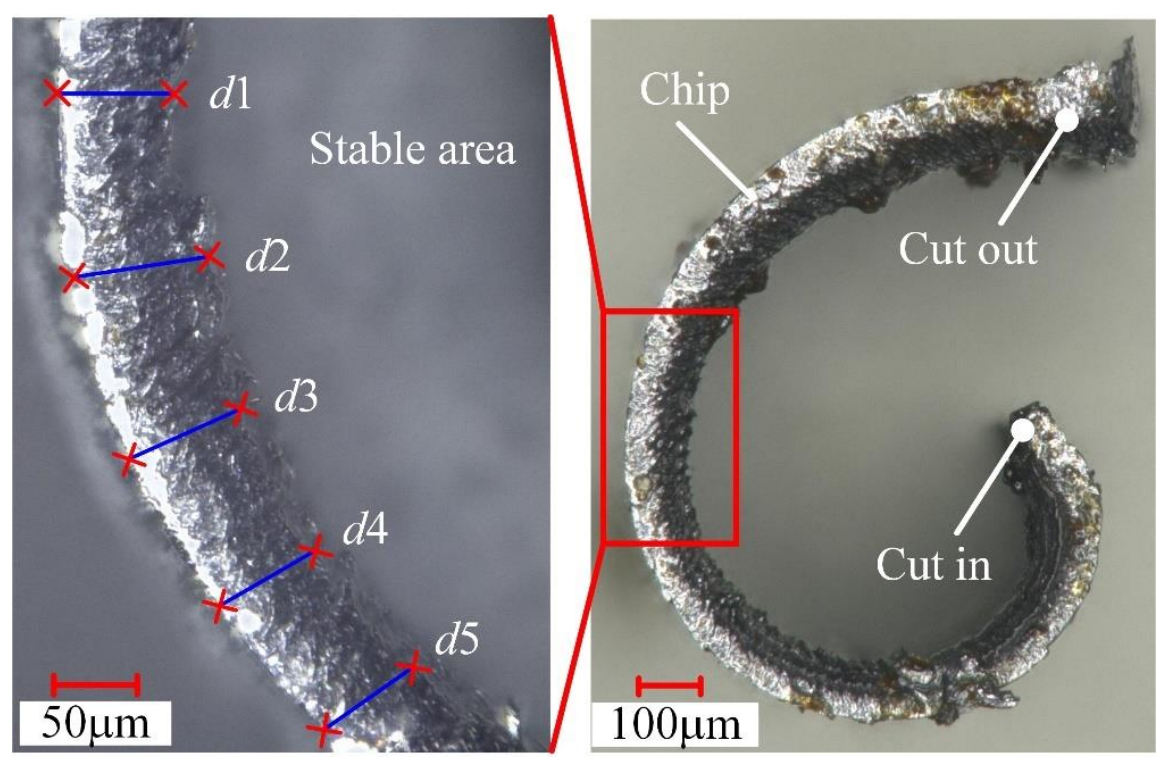




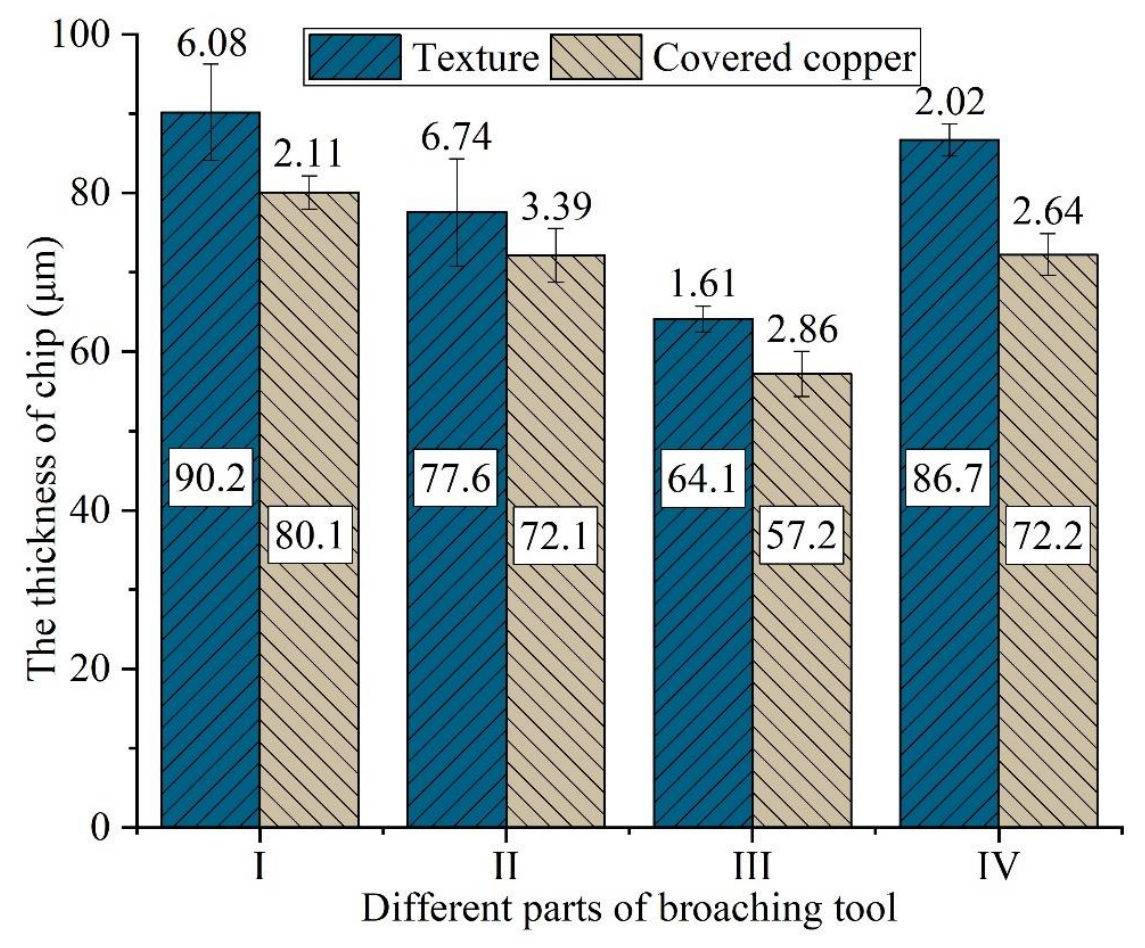




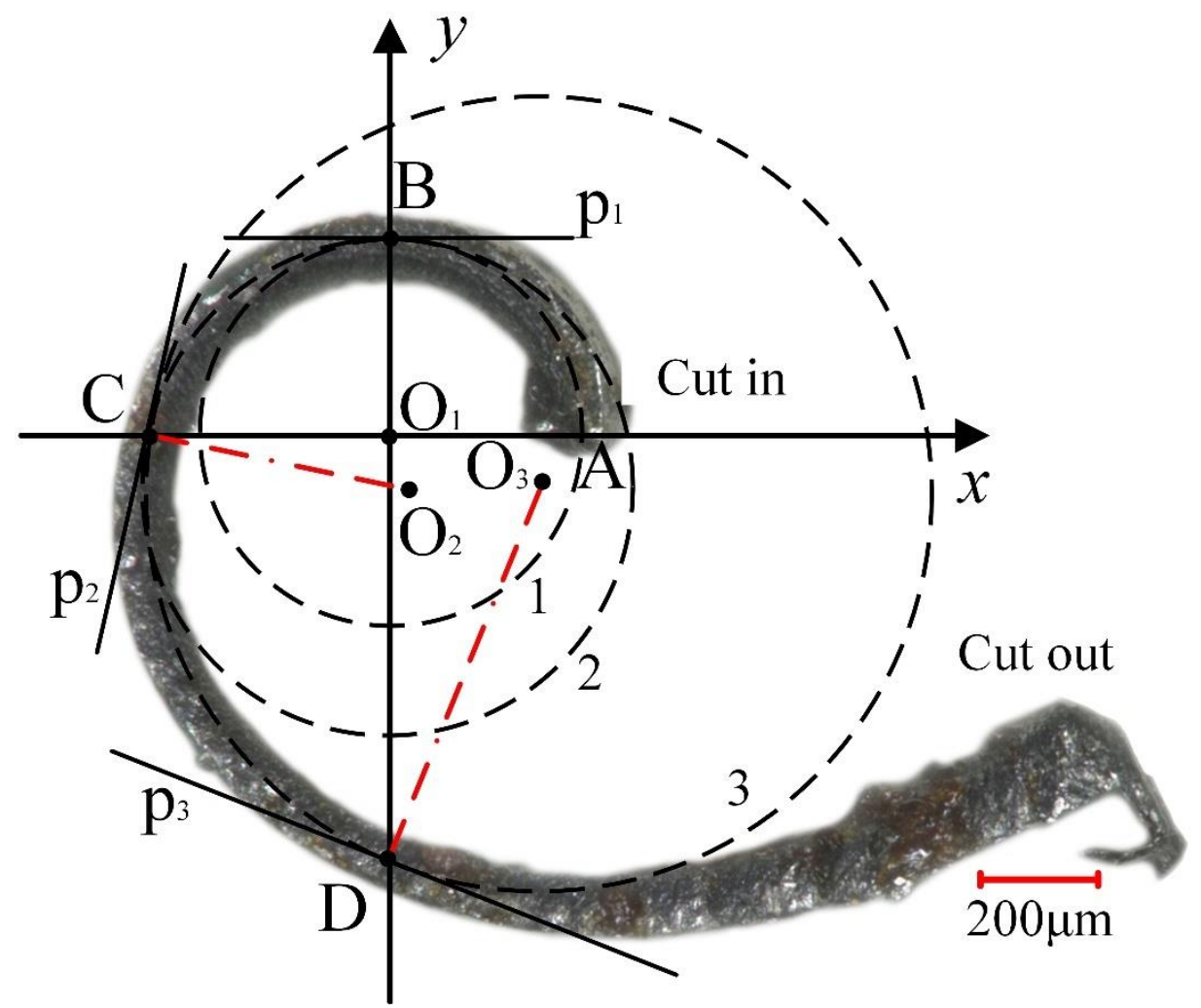



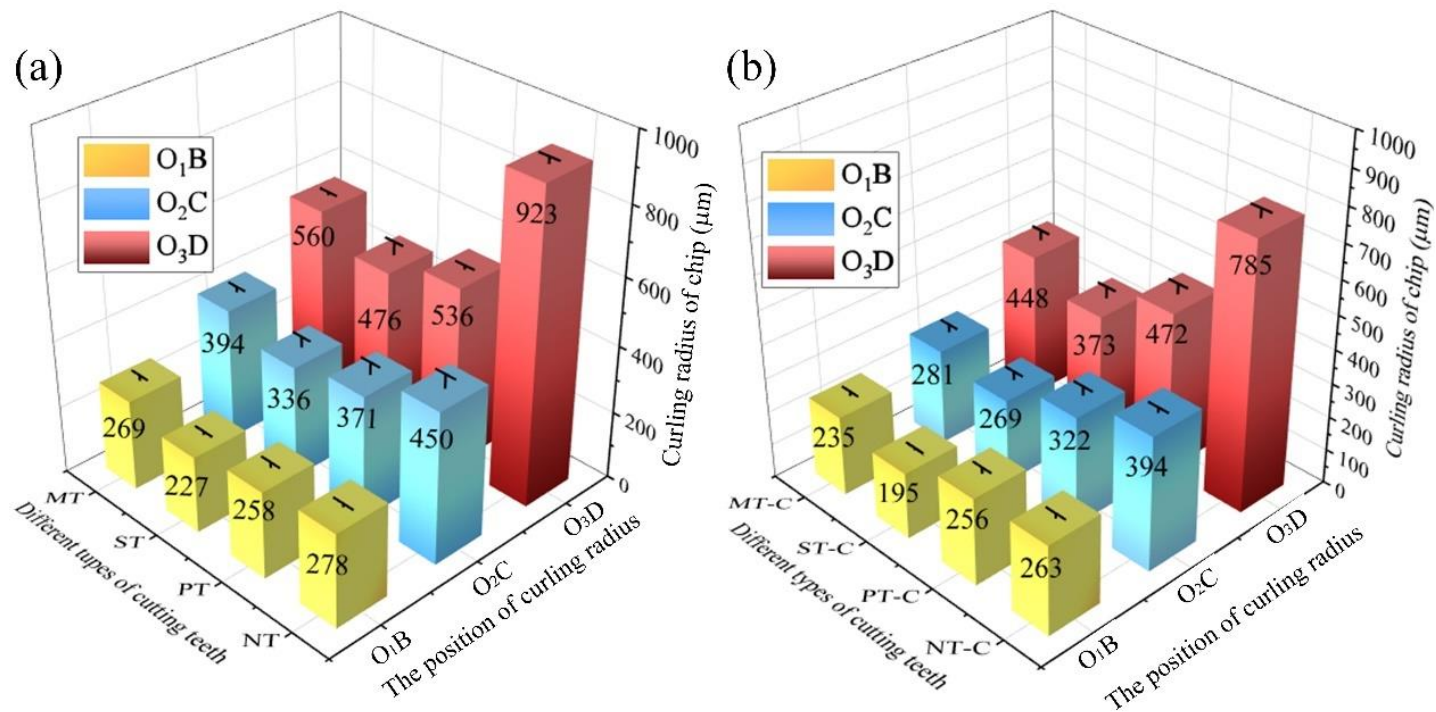


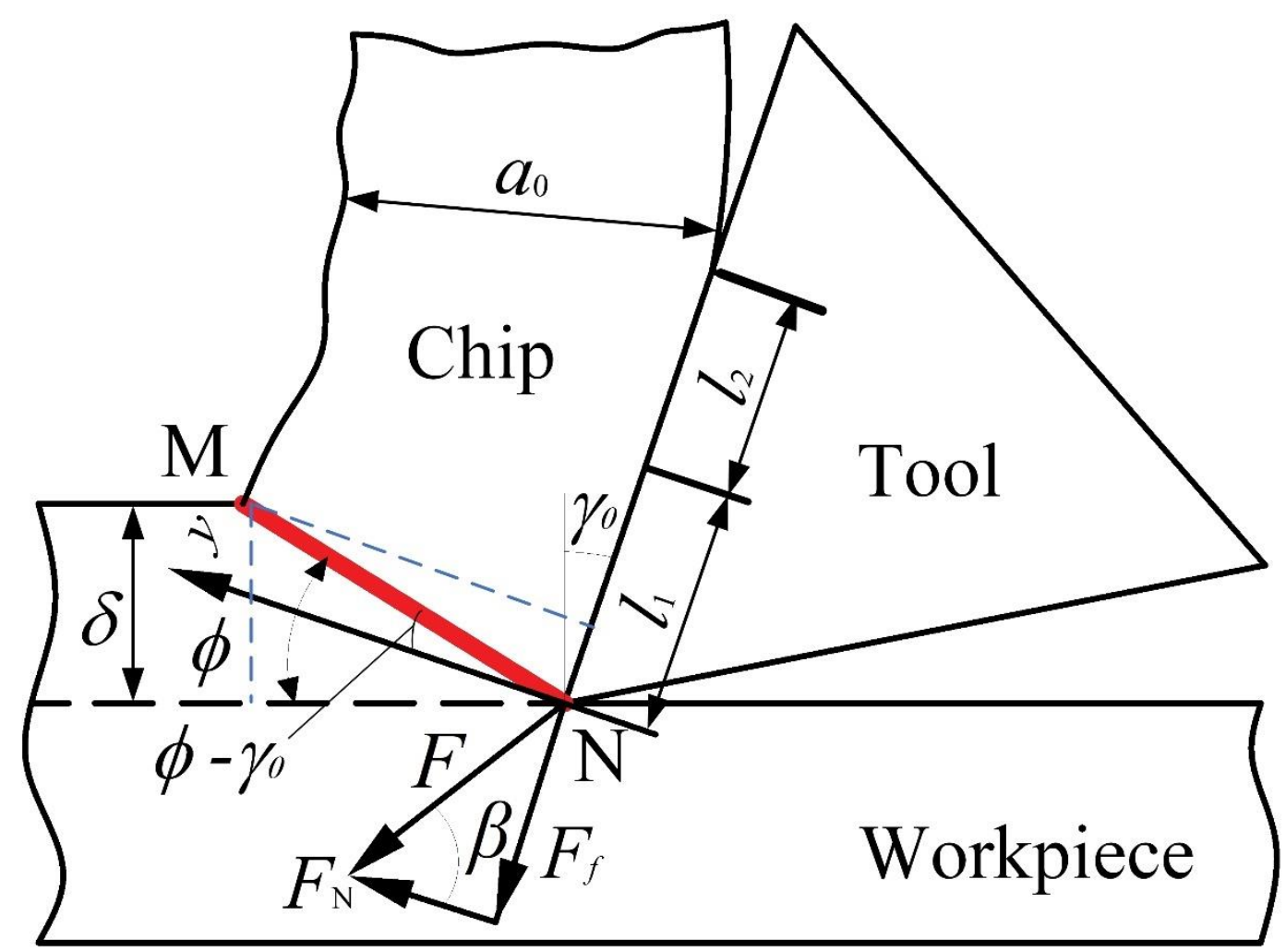



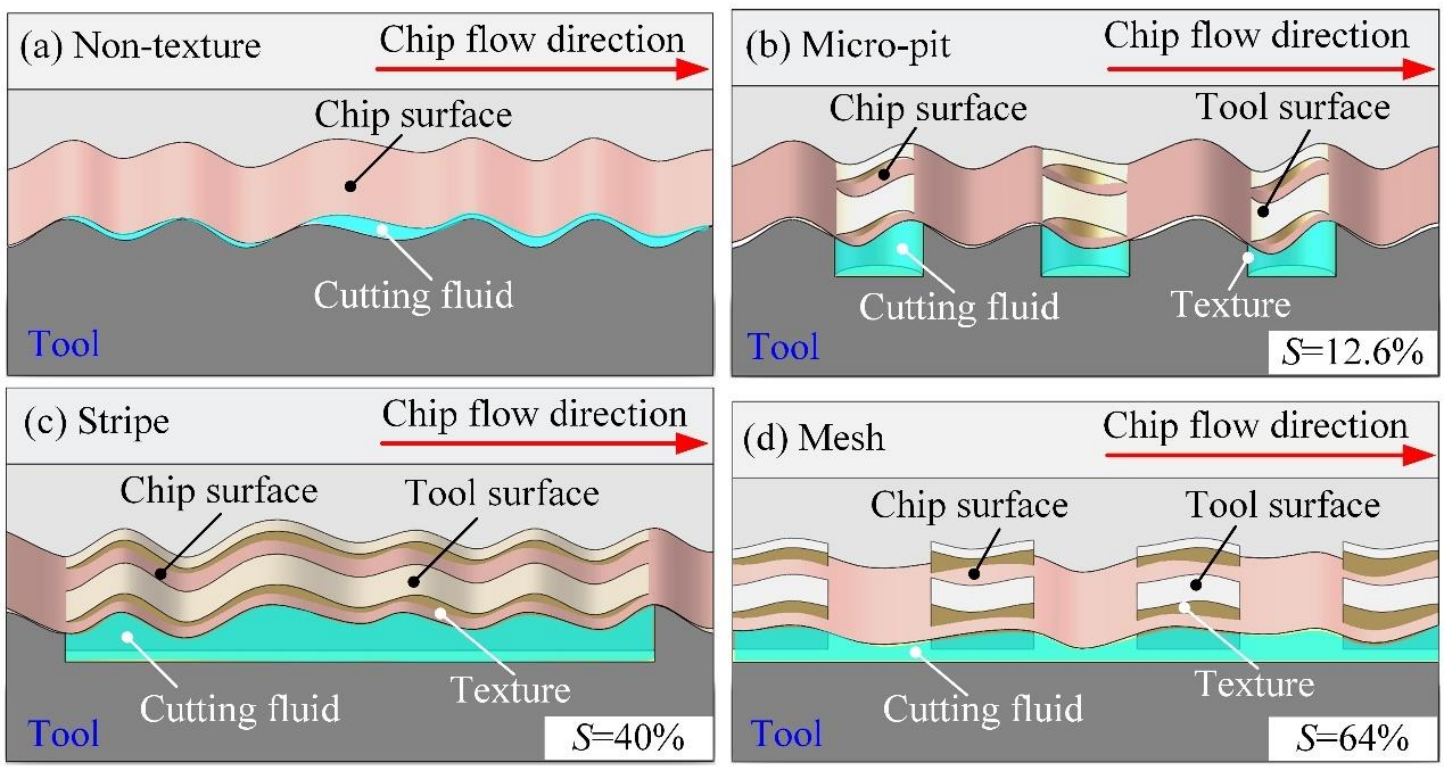


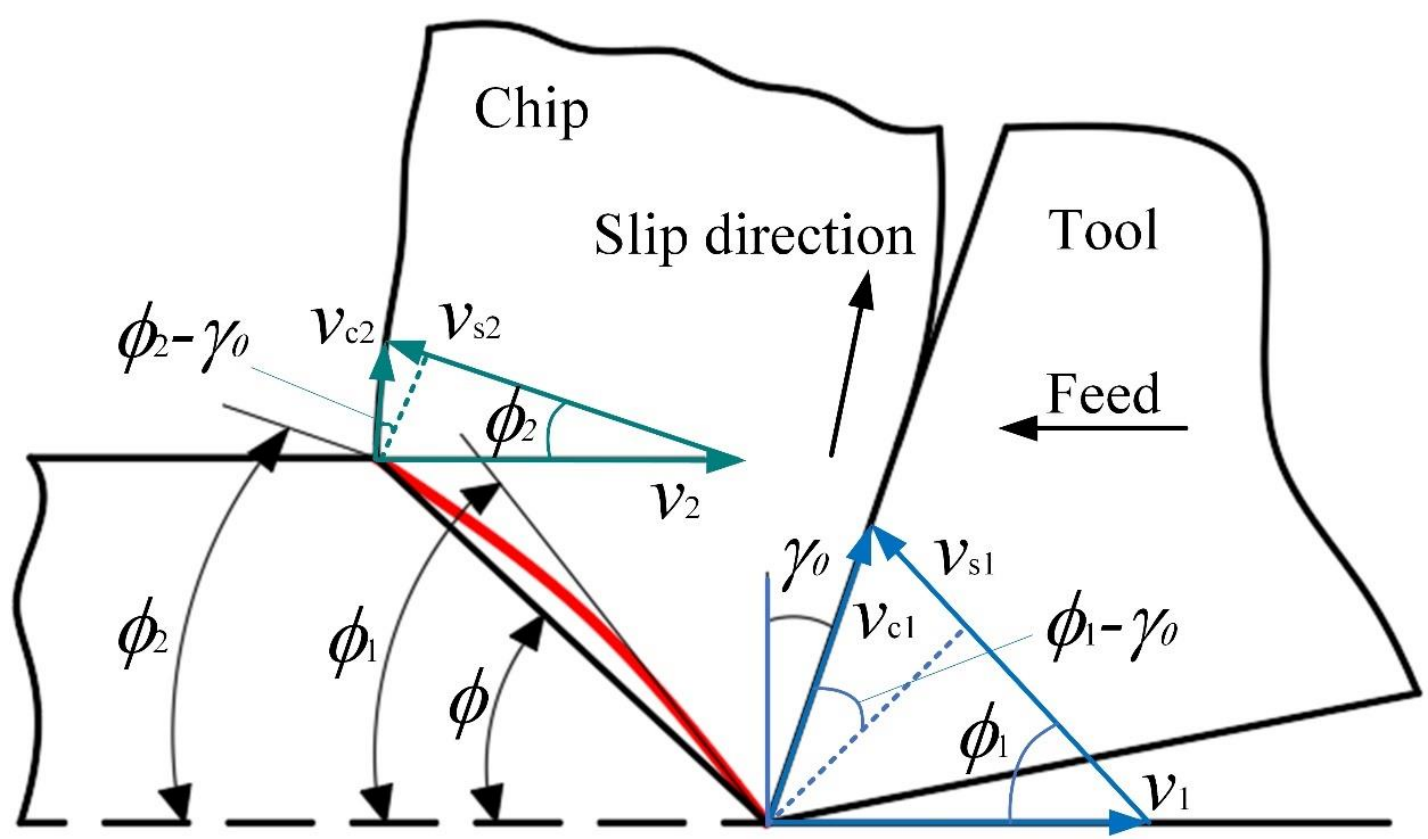




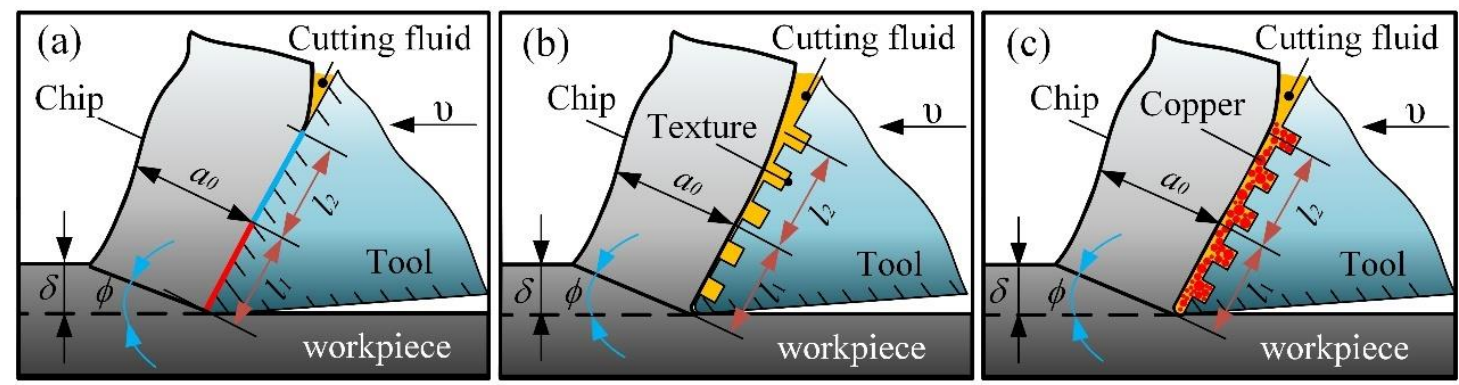




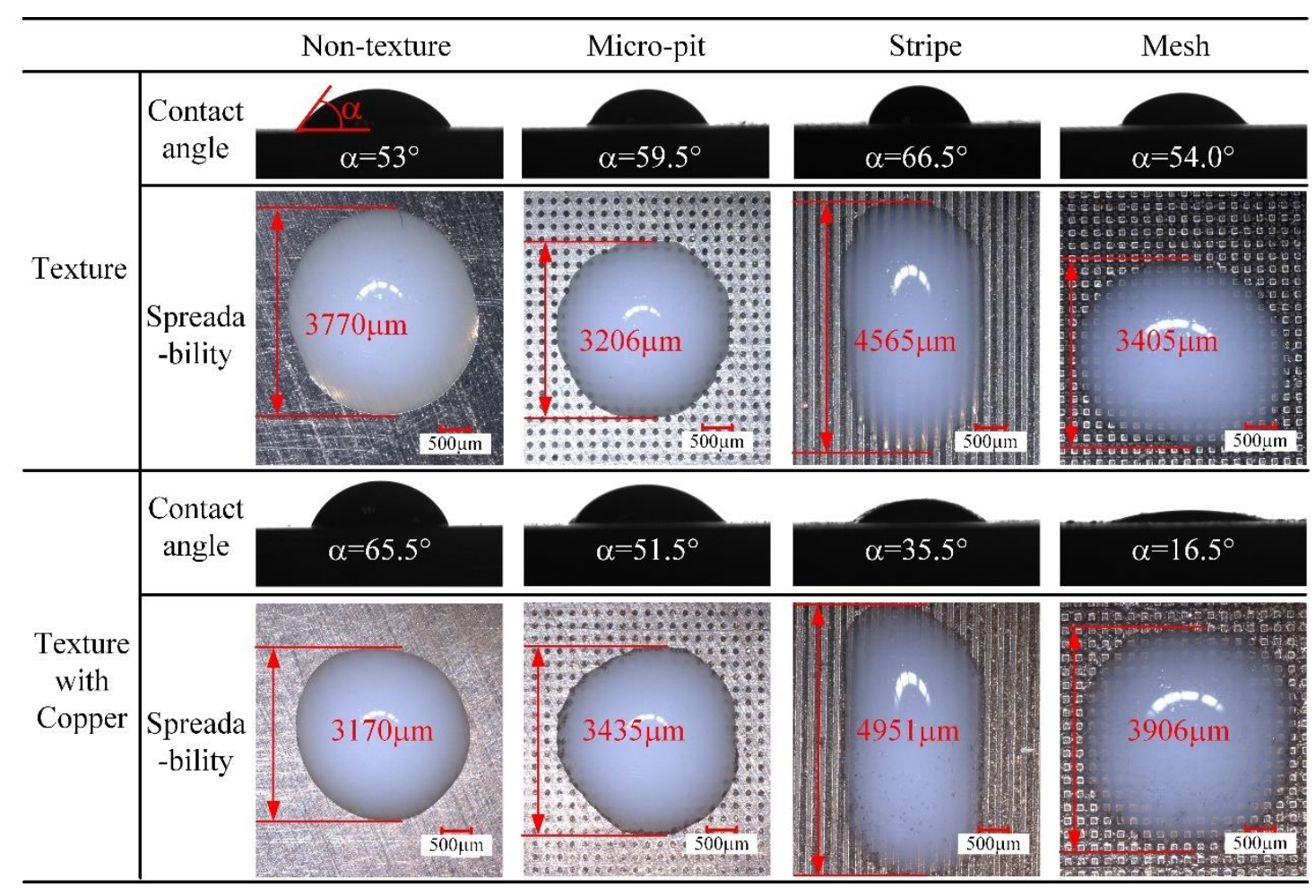



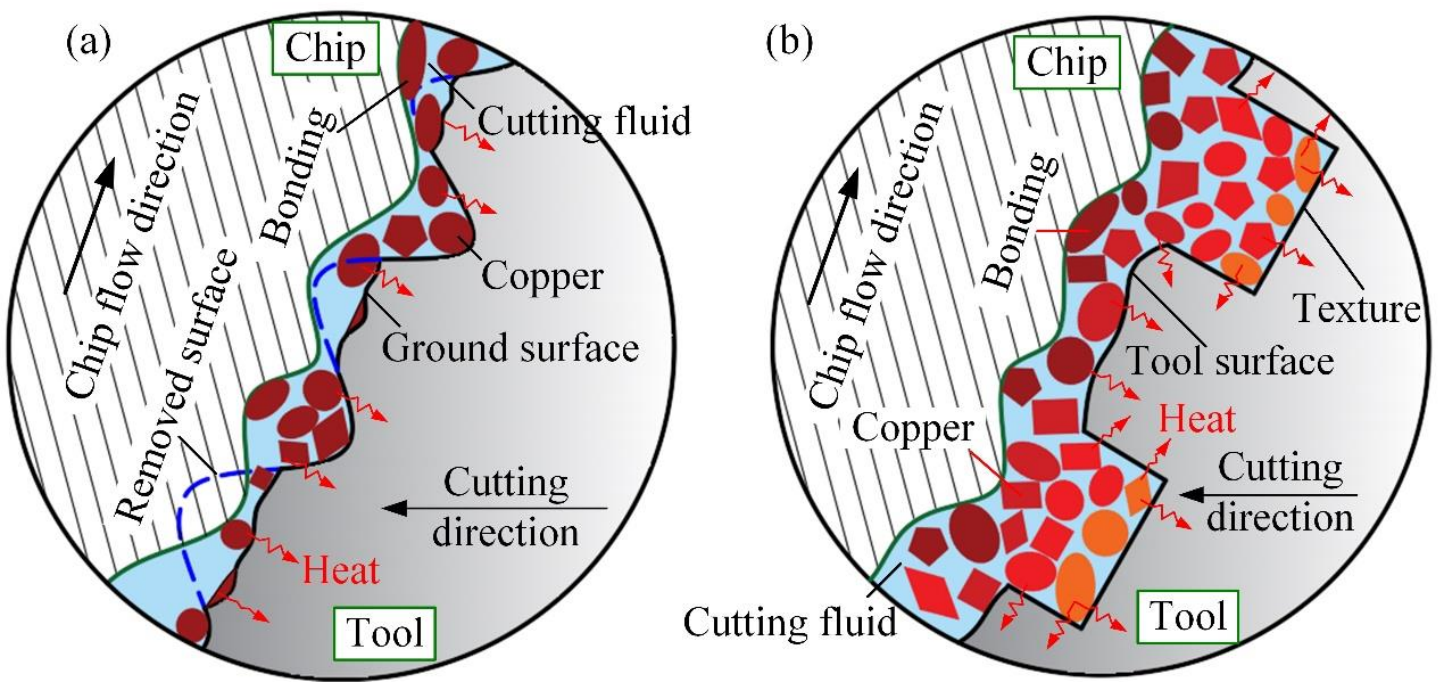